Article

\title{
The Use of National CORS Networks for Determining Temporal Mass Variations within the Earth's System and for Improving GRACE/GRACE-FO Solutions
}

\author{
Walyeldeen Godah *, Jagat Dwipendra Ray, Malgorzata Szelachowska and Jan Krynski \\ Institute of Geodesy and Cartography, Centre of Geodesy and Geodynamics, 27 Modzelewskiego St., \\ 02-679 Warsaw, Poland; Jagat.Ray@igik.edu.pl (J.D.R.); malgorzata.szelachowska@igik.edu.pl (M.S.); \\ jan.krynski@igik.edu.pl (J.K.) \\ * Correspondence: walyeldeen.godah@igik.edu.pl; Tel.: +48-22-3291903
}

Received: 19 August 2020; Accepted: 13 October 2020; Published: 15 October 2020

check for updates

\begin{abstract}
Temporal mass variations within the Earth's system can be detected on a regional/global scale using GRACE (Gravity Recovery and Climate Experiment) and GRACE Follow-On (GRACE-FO) satellite missions' data, while GNSS (Global Navigation Satellite System) data can be used to detect those variations on a local scale. The aim of this study is to investigate the usefulness of national GNSS CORS (Continuously Operating Reference Stations) networks for the determination of those temporal mass variations and for improving GRACE/GRACE-FO solutions. The area of Poland was chosen as a study area. Temporal variations of equivalent water thickness $\triangle E W T$ and vertical deformations of the Earth's surface $\Delta h$ were determined at the sites of the ASG-EUPOS (Active Geodetic Network of the European Position Determination System) CORS network using GRACE/GRACE-FO-based GGMs and GNSS data. Moreover, combined solutions of $\triangle E W T$ were developed by combining $\triangle E W T$ obtained from GNSS data with the corresponding ones determined from GRACE satellite mission data. Strong correlations (correlation coefficients ranging from 0.6 to 0.9 ) between detrended $\Delta h$ determined from GRACE/GRACE-FO satellite mission data and the corresponding ones from GNSS data were observed at $93 \%$ of the GNSS stations investigated. Furthermore, for the determination of temporal mass variations, GNSS data from CORS network stations provide valuable information complementary to GRACE satellite mission data.
\end{abstract}

Keywords: equivalent water thickness; GNSS; GRACE/GRACE-FO; temporal mass variations within the Earth's system; vertical surface deformation

\section{Introduction}

The determination of temporal mass variations in the Earth's system with high accuracy as well as high spatial and temporal resolutions using space geodetic data is one of the main scientific problems in the Earth science-related disciplines. Since the last decade, the Gravity Recovery and Climate Experiment (GRACE; [1]) satellite mission operated between March 2002 and October 2017, brought a unique opportunity for the determination of temporal mass variations within the Earth's system. Its concept, including theoretical background as well as impressive scientific results, has widely been demonstrated by many authors (e.g., see the review given by [2]). The tremendous success achieved from the mission emphasized the need of launching a GRACE-type mission for a sustainable long-term monitoring of temporal mass variations within the Earth's system. The GRACE Follow-On (GRACE-FO; https://gracefo.jpl.nasa.gov/) satellite mission of a designed life of five years has been launched in May 2018. The GRACE and GRACE-FO missions, without any doubt, are a state-of-the-art space geodetic technique for monitoring temporal mass variations within the Earth's system. They have 
clearly revolutionized research in many disciplines of Earth sciences. Besides GRACE-type satellite missions, the Global Navigation Satellite System (GNSS) has proven itself as one of the most powerful space geodesy tools for the determination of temporal mass variations in the Earth's system and related geodynamic processes. It is successfully used to study the elastic ground loading deformation in response to the Earth's hydrological mass variations. Since the beginning of this century, numerous studies on the relation between the mass loading and the Earth's surface deformations obtained from GNSS data have been conducted on a global scale (e.g., [3-7]), on a continental scale, e.g., South America [8]; and Europe [9], as well as on a local/regional scale, e.g., Japan [10]; the Amazon basin [11]; Bangladesh [12]; Greenland [13]; the West Africa [14]; North America [15-18]; China [19-22]; Tibet [23,24]; Poland [25,26]; and the East Africa [27]. Except van Dam et al. [9] that indicated poor correlation between the annual vertical crustal deformation from GRACE and GPS at 36 GPS sites over Europe, all those studies revealed very good agreement (correlation coefficient $>0.6$ ) between the Earth's surface deformations obtained from GNSS data and the corresponding ones determined from GRACE data. In addition to GNSS and GRACE data, other space geodetic techniques, e.g., the very long baseline interferometry (VLBI), indicated that the vertical crustal deformations due to continental water loading reach up to $15 \mathrm{~mm}$ [28].

The latest official GRACE/GRACE-FO level-2 products, i.e., RL06 (release 6) GRACE/ GRACE-FO-based Global Geopotential Models (GGMs), developed by GFZ (GeoForschungsZentrum), CSR (Center for Space Research) and JPL (Jet Propulsion Laboratory) centers (cf. [29-32]) are currently available for scientific users. In addition to GRACE/GRACE-FO-based GGMs, global mass concentration (mascon) products of NASA (National Aeronautics and Space Administration), GSFC (Goddard Space Flight Center), JPL and CSR have also been released to the scientific community [33-35]. On the other hand, national GNSS CORS (Continuously Operating Reference Stations) networks are rapidly growing and being continuously expanded around the world. Currently, national GNSS CORS networks are in operation in Australia, North America and almost all European countries (e.g., networks of the EUPOS multifunctional reference stations) as well as in some countries in Africa, Asia and South America. National GNSS CORS networks are regarded as a multifunctional precise positioning system that provides very valuable information for: (1) static and Real-Time Kinematic (RTK) positioning; (2) monitoring crustal deformations; (3) definition and realization of global, regional and national geodetic reference frames; (4) atmosphere related studies; etc. Besides national GNSS CORS networks, a number of dense regional/local GNSS CORS networks have been established for a specific scientific research, e.g., the $\mathrm{PBO} \mathrm{H}_{2} \mathrm{O}$ (Plate Boundary Observatory Studies of the Water Cycle) established to study the 3D strain field resulting from deformation across the active boundary zone between the Pacific and North American plates in the western United States as well as remotely measured changes in soil moisture content, snow depth, water content of the troposphere, and ground motions related to changes in the water table (e.g., [36]).

The coarse spatial resolution of GRACE/GRACE-FO products is one of the main weaknesses of GRACE-type missions. Moreover, GRACE/GRACE-FO level-2 products (e.g., GRACE/GRACE-FO-based GGMs) as well as GRACE-based mascon products being the results of a complex processing of GRACE mission data, are released to scientific users with a delay of a few months. On the other hand, temporal mass variations can be obtained using GNSS data in real or near real time, but they represent the local effect for a very limited area within the radius of a few kilometers from a GNSS station. Furthermore, coordinate variations obtained from GNSS data are affected by many errors, e.g., the draconitic error that systematically affects the seasonal periods in GNSS series (e.g., [37]). However, investigation concerning the use of national GNSS CORS networks to study temporal mass variations within the Earth's system is essentially needed. The main objective of this study is to investigate the use of national GNSS CORS networks for monitoring temporal mass variations within the Earth's system. It is also aimed at the use of national GNSS CORS networks data to improve temporal mass variations within the Earth's system on a regional/local scale determined from GRACE/GRACE-FO satellite missions' data. The study area and data used are described in 
Section 2. In Section 3, the methods implemented for the determination of vertical deformations of the Earth's surface $\Delta h$ and temporal variations of equivalent water thickness using GRACE/GRACE-FO satellite mission and GNSS data as well as the determination of $\triangle E W T$ combined solutions using these data are specified. The results obtained are presented and analyzed in Section 4. Moreover, in Section 4, the improvement of $\triangle E W T$ determined from GRACE satellite mission data when adding $\triangle E W T$ determined from GNSS data is illustrated. Finally, in Section 5, discussions and conclusions concerning the usefulness of GNSS data from CORS network stations for the determination of $\Delta h$ and $\triangle E W T$ as well as for improving GRACE/GRACE-FO solutions are given.

\section{Study Area and Data Used}

The area of Poland has been chosen as a study area. A national GNSS CORS network in this area, called the Active Geodetic Network of the European Position Determination System (ASG-EUPOS), consists recently of 102 GNSS stations apart from each other by about $70 \mathrm{~km}$; http://www.asgeupos.pl, are operating since 2008. Daily GNSS data from 96 ASG-EUPOS stations covering the period 2008-2018 were used within the course of this study. Figure 1 illustrates the study area as well as the ASG-EUPOS sites used.

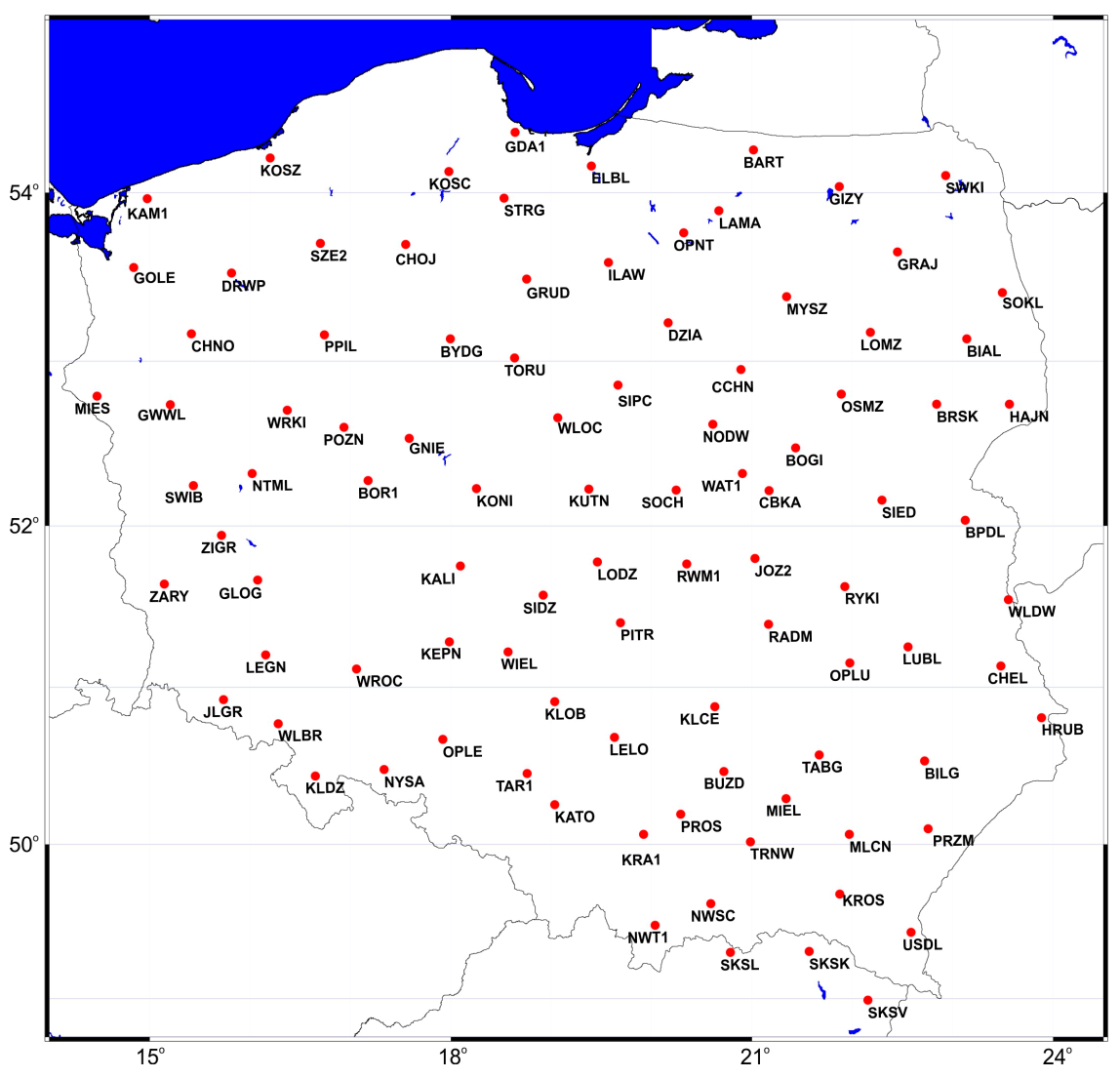

Figure 1. Study area and the location of Global Navigation Satellite System (GNSS) stations used.

Beside the GNSS data from ASG-EUPOS stations, CSR RL06 GRACE/GRACE-FO-based GGMs were utilized in this study. In order to reduce the noise included in RL06 GRACE/GRACE-FO-based GGMs, the DDK3 (decorrelation 3) filter (cf. [38]) that indicates a good performance over the area investigated [39], was applied. Moreover, CSR RL06 GRACE/GRACE-FO-based GGMs developed as monthly solutions obtained from GRACE/GRACE-FO satellite missions were truncated at $\mathrm{d} / \mathrm{o} 60$ that corresponds to the spatial resolution, i.e., $3^{\circ} \times 3^{\circ}$ at the equator.

The WaterGAP Global Hydrology Model (WGHM) Version 2.2d (e.g., [40,41]) was used for the evaluation purposes. This hydrological model represents the terrestrial hydrological cycle with a 
spatial resolution of 0.5 degree. Within the context of the investigation conducted in this study, monthly variations of equivalent water thickness for the period 2008-2016 were obtained at the ASG-EUPOS sites from the WGHM.

\section{Methods}

The methods implemented for the determination of monthly vertical deformations of the Earth's surface and monthly variations of equivalent water thickness from GRACE/GRACE-FO-based GGMs and GNSS data are described in Sections 3.1 and 3.2, respectively. In Section 3.3, the method applied to determine combined solutions of monthly variations of equivalent water thickness $\Delta E W T_{\mathrm{m} \text {-CombSol }}$ is presented. In Section 3.4, uncertainties of monthly variations of equivalent water thickness determined from GNSS and GRACE/GRACE-FO satellite missions' data as well as their combined solutions are estimated. The general steps of the method implemented within this investigation are summarized in Figure 2.

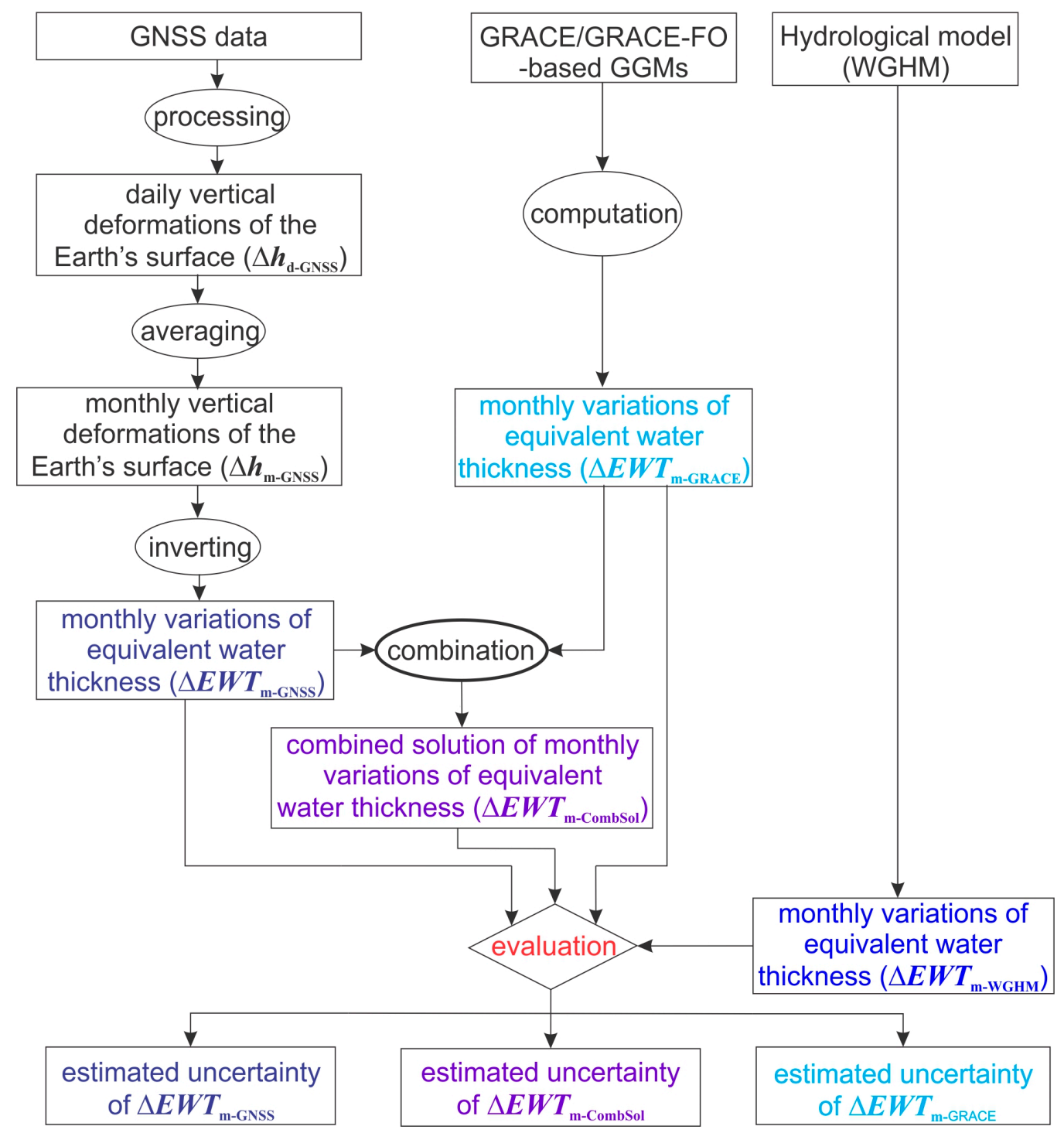

Figure 2. General steps of the method implemented to determine combined solutions of $\triangle E W T$ and evaluate monthly variations of equivalent water thickness from Gravity Recovery and Climate Experiment/GRACE-Follow-On (GRACE/GRACE-FO)-based Global Geopotential Models (GGMs) and GNSS data. 


\subsection{The Determination of $\triangle h_{m-G R A C E}$ and $\triangle E W T_{m-G R A C E}$}

Monthly vertical deformations of the Earth's surface $\Delta h_{\mathrm{m} \text {-GRACE }}$ and monthly variations of equivalent water thickness $\triangle E W T_{\mathrm{m} \text {-GRACE }}$ were determined at the sites of the ASG-EUPOS CORS network using GRACE/GRACE-FO-based GGMs as follows [9,20,42,43]:

$$
\begin{gathered}
\Delta h_{\mathrm{m}-\mathrm{GRACE}}=a \sum_{n=0}^{N_{\max }} \sum_{m=0}^{n} P_{n m}(\sin \varphi) \frac{h_{n}}{1+k_{n}}\left(\Delta C_{n m} \cos m \lambda+\Delta S_{n m} \sin m \lambda\right) \\
\Delta E W T_{\mathrm{m}-\mathrm{GRACE}}=\frac{a \times \rho_{\text {avg }}}{3 \rho_{w}} \sum_{n=0}^{N_{\max }} \sum_{m=0}^{n} P_{n m}(\sin \varphi) \frac{2 n+1}{1+k_{n}}\left(\Delta C_{n m} \cos m \lambda+\Delta S_{n m} \sin m \lambda\right)
\end{gathered}
$$

where $\varphi, \lambda$ are spherical geocentric coordinates of the computation point, $a$ is the radius of the Earth (semi-major axis), $\rho_{w}$ is the water density, $\rho_{a v g}$ is the Earth's average density, $k$ and $h$ are load Love numbers of degree $n$ based on the Preliminary Reference Earth Model (PREM; [44]) obtained from [45], $\Delta C_{n m}$ and $\Delta S_{n m}$ are the differences between fully normalized spherical harmonic coefficients from monthly RL06 GRACE/GRACE-FO-based GGMs and the corresponding ones obtained from a reference GGM, $P_{n m}$ are the fully normalized Legendre functions of degree $n$ and order $m$, and $N_{\max }$ is the maximum degree applied.

The $P_{n m}(\sin \varphi)$ are determined using a recursive algorithm as follows (e.g., [46]):

$$
\left.\begin{array}{rl}
P_{00}(\sin \varphi) & =1.0 \\
P_{11}(\sin \varphi) & =\sqrt{3} \cos \varphi \\
P_{n n}(\sin \varphi) & =\sqrt{\frac{(2 n+1)}{n} \cos \varphi P_{(n-1)(n-1)}(\sin \varphi)} \\
P_{n m}(\sin \varphi) & =\sqrt{\frac{(2 n-1)(2 n+1)}{(n-m)(n+m)}} \cos \varphi P_{(n-1) m}(\sin \varphi) \\
& -\sqrt{\frac{(2 n+1)(n+m-1)(n-m-1)}{(2 n+3)(n+m)(n-m)}} \cos \varphi P_{(n-2) m}(\sin \varphi)
\end{array}\right\}
$$

In this study, $\Delta h_{\mathrm{m} \text {-GRACE }}$ and $\triangle E W T_{\text {m-GRACE }}$ were determined using CSR RL06 GRACE/GRACE-FO-based GGMs specified in Section 2 and the IGiK-TVGMF software [43]. These GGMs were obtained from the International Centre for Global Earth Models (ICGEM; cf. http://icgem.gfz-potsdam.de/series). The degree- 1 and degree-2 spherical harmonic coefficients of these GGMs were replaced by the corresponding ones obtained from the solution described in [47] and from Satellite Laser Ranging (SLR) observations [48], respectively. The monthly estimates of these degree-1 and degree-2 spherical harmonic coefficients are available via GRACE TN-13 (GRACE Technical Note 13; https://podaac-tools.jpl.nasa.gov/drive/files/allData/grace/docs/TN-13_GEOC_CSR_RL06.txt) and GRACE TN-11 (GRACE Technical Note 11; cf. https://podaac-tools.jpl.nasa.gov/drive/files/allData/ grace/docs/TN-11_C20_SLR.txt), respectively. The EGM2008 (Earth Gravitational Model 2008; [49]) was used as a reference GGM and the WGS84 (World Geodetic System 1984) was chosen as a geodetic reference system.

\subsection{The Determination of $\Delta h_{m-G N S S}$ and $\triangle E W T_{m \text {-GNSS }}$ from GNSS Data}

Daily vertical deformations of the Earth's surface $\Delta h_{\text {d-GNSS }}$ for the period 2008-2018 were determined first at the location of 96 sites of the ASG-EUOPS CORS network using daily GNSS observations data processed by the GAMIT/GLOBK software version 10.7 [50,51]. The TEQC (Translation, Editing, and Quality Checking) software developed by UNAVCO [52] was used to check the quality of GNSS data from 96 stations of the ASG-EUPOS network. The linear combination of L1 and L2 was implemented to eliminate the signal delay caused by first-order ionospheric refraction. The delay induced by second- and third-order ionospheric refraction of the carrier wave was also removed using daily IONEX (IONosphere EXchange) files provided by the Centre for Orbit 
Determination in Europe (CODE; [53]). These IONEX files represent the ionosphere in the form of global maps of the Vertical Total Electron Content (VTEC). The troposphere delay was estimated using the Vienna Mapping Function (VMF; [54]) with a priori hydrostatic delay estimates based on the global pressure and temperature (GPT2) model [55]. The troposphere delay was estimated for every $2 \mathrm{~h}$ from GNSS data acquired at ASG-EUPOS sites investigated. The Atmospheric Loading Model (ATML; [56]) at the observation level provided by the MIT (Massachusetts Institute of Technology) was applied to remove deformation caused by atmospheric loading. The Finite Element Solutions 2004 tidal model (FES2004; [57]) was used to remove deformations induced from oceanic tidal loading.

From the GAMIT software, the daily loosely constrained solutions were obtained. These solutions were combined with global solutions provided by the MIT using the GLOBK software. In this step of processing, the GLORG was used to define the reference frame. Time series of daily vertical deformations of the Earth's surface were tight to the ITRF2014 (International Terrestrial Reference Frame 2014; [58]). Daily vertical deformations of the Earth's surface that exceed the daily repeatability within the same month were considered as outliers. These outliers were detected using GAMIT/GLOBK MATLAB TOOL [50] and subsequently removed. Finally, all daily vertical deformations of each month were averaged to estimate monthly vertical deformations of the Earth's surface $\Delta h_{\mathrm{m} \text {-GNSS. Time series }}$ of daily and monthly vertical deformations for an exemplary ASG-EUPOS station KLCE are shown

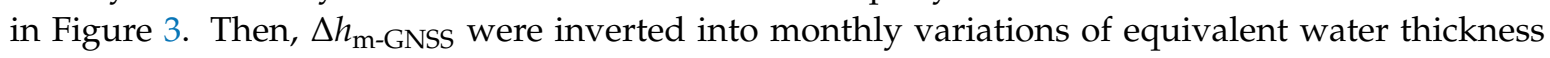
$\Delta E W T_{\mathrm{m}-\mathrm{GNSS}}$ using the Green's function elastic half-space model (cf. [59]).

$$
\Delta E W T_{\mathrm{m}-\mathrm{GNSS}}=\Delta h_{\mathrm{m}-\mathrm{GNSS}} \cdot\left(2 \rho_{w} \cdot R_{0} \cdot g \cdot\left(\frac{1-v^{2}}{E}\right)\right)^{-1}
$$

where $R_{0}$ presents the radius that has been estimated on the basis of the spatial resolution of GRACE/GRACE-FO satellite missions' data (i.e., $167 \mathrm{~km}$ ), $g$ denotes the gravity value (estimated to $9.81 \mathrm{Gal}), v$ is the Poisson's ratio, $E$ is the Young's modulus. It should be noted that on the basis of the review of the literature (e.g., [59]), the Poisson's ratio and the Young's modulus used in this study were estimated to 0.25 and $70 \mathrm{Gpa}$, respectively.

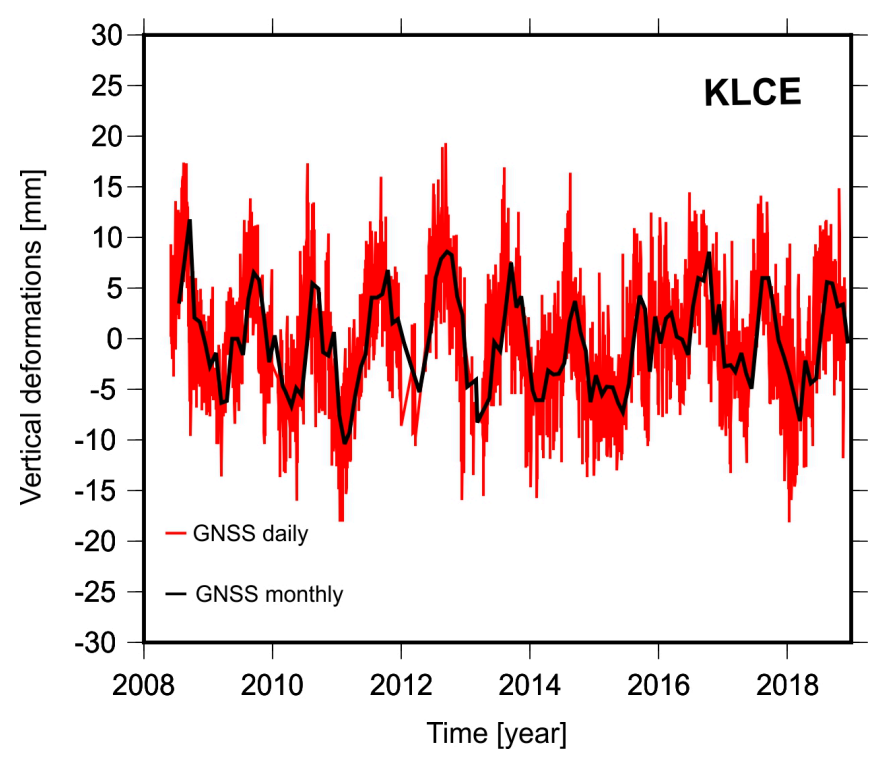

Figure 3. Time series of daily and monthly vertical deformations for the KLCE station of the Active Geodetic Network of the European Position Determination System (ASG-EUPOS) network. 


\subsection{The Detrmination of $\triangle E W T_{m-C o m b S o l}$}

Combined solutions of monthly variations of equivalent water thickness $\Delta E W T_{\mathrm{m} \text {-Combsol were }}$ developed for each $(i=1,2,3, \ldots, q)$ GNSS station of the ASG-EUPOS CORS network:

$$
\Delta E W T_{\mathrm{m}-\mathrm{CombSol}}^{i}=\frac{w_{\mathrm{GNSS}}^{i} \cdot \Delta E W T_{\mathrm{m}-\mathrm{GNSS}}^{i}+w_{\mathrm{GRACE}}^{i} \cdot \Delta E W T_{\mathrm{m}-\mathrm{GRACE}}^{i}}{w_{\mathrm{GNSS}}^{i}+w_{\mathrm{GRACE}}^{i}}
$$

where $q$ denotes the total number of GNSS stations of the ASG-EUPOS CORS network investigated and $w_{\text {GNSS }}$ and $w_{\text {GRACE }}$ are weights for $\triangle E W T$ determined from GNSS and GRACE/GRACE-FO satellite missions' data, respectively. These weights were estimated as follows:

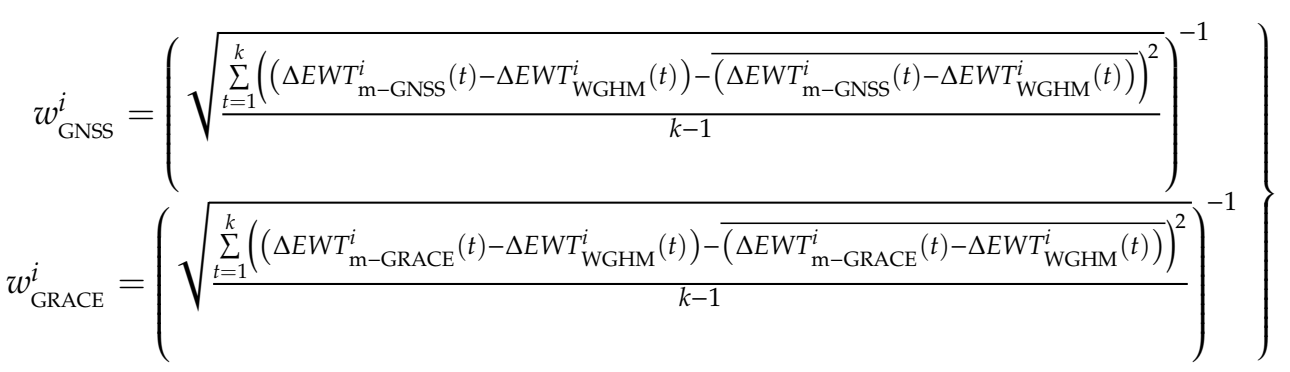

where $(t=1,2,3, \ldots, k)$ denotes the month, $k$ is the total number of months investigated, $\triangle E W T_{\mathrm{m}-W G H M}$ are time series of monthly variations of the equivalent water thickness obtained from the WGHM and the overbar operator presents the average over all $k$ months.

\subsection{Estimation of $\triangle E W T_{m-G R A C E}, \Delta E W T_{m-G N S S}$, and $\Delta E W T_{m \text {-CombSol }}$ Uncertainties}

Monthly variations of equivalent water thickness determined from GNSS data and GRACE/GRACE-FO-based GGMs as well as their combined solutions determined with the use of methods specified in Section 3.1, Section 3.2, Section 3.3, were evaluated using $\Delta E W T_{\mathrm{m}-W G H M}$. The differences

$$
\left.\begin{array}{l}
\delta \Delta E W T_{\mathrm{m}-\mathrm{GRACE}}^{i}=\Delta E W T_{\mathrm{m}-\mathrm{WGHM}}^{i}-\Delta E W T_{\mathrm{m}-\mathrm{GRACE}}^{i} \\
\delta \Delta E W T_{\mathrm{m}-\mathrm{GNSS}}^{i}=\Delta E W T_{\mathrm{m}-\mathrm{WGHM}}^{i}-\Delta E W T_{\mathrm{m}-\mathrm{GNSS}}^{i} \\
\delta \Delta E W T_{\mathrm{m}-\mathrm{CombSol}}^{i}=\Delta E W T_{\mathrm{m}-\mathrm{WGHM}}^{i}-\Delta E W T_{\mathrm{m}-\mathrm{ComSol}}^{i}
\end{array}\right\}
$$

were determined and standard deviations of these differences were computed. Moreover, correlations between equivalent water thickness obtained from the WGHM and the corresponding ones determined from GNSS and GRACE/GRACE-FO satellite missions' data as well as the combined solutions $\triangle E W T_{\mathrm{m}-\mathrm{CombSol}}$ developed were estimated.

\section{Results}

\subsection{Monthly Vertical Deformations of the Earth's Surface}

Time series of monthly vertical deformations of the Earth's surface $\Delta h$ at the stations of

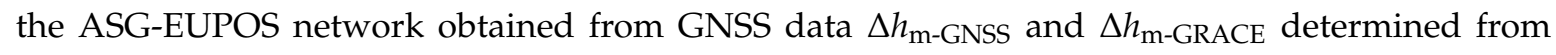
GRACE/GRACE-FO satellite missions' data are illustrated in Figure 4. 


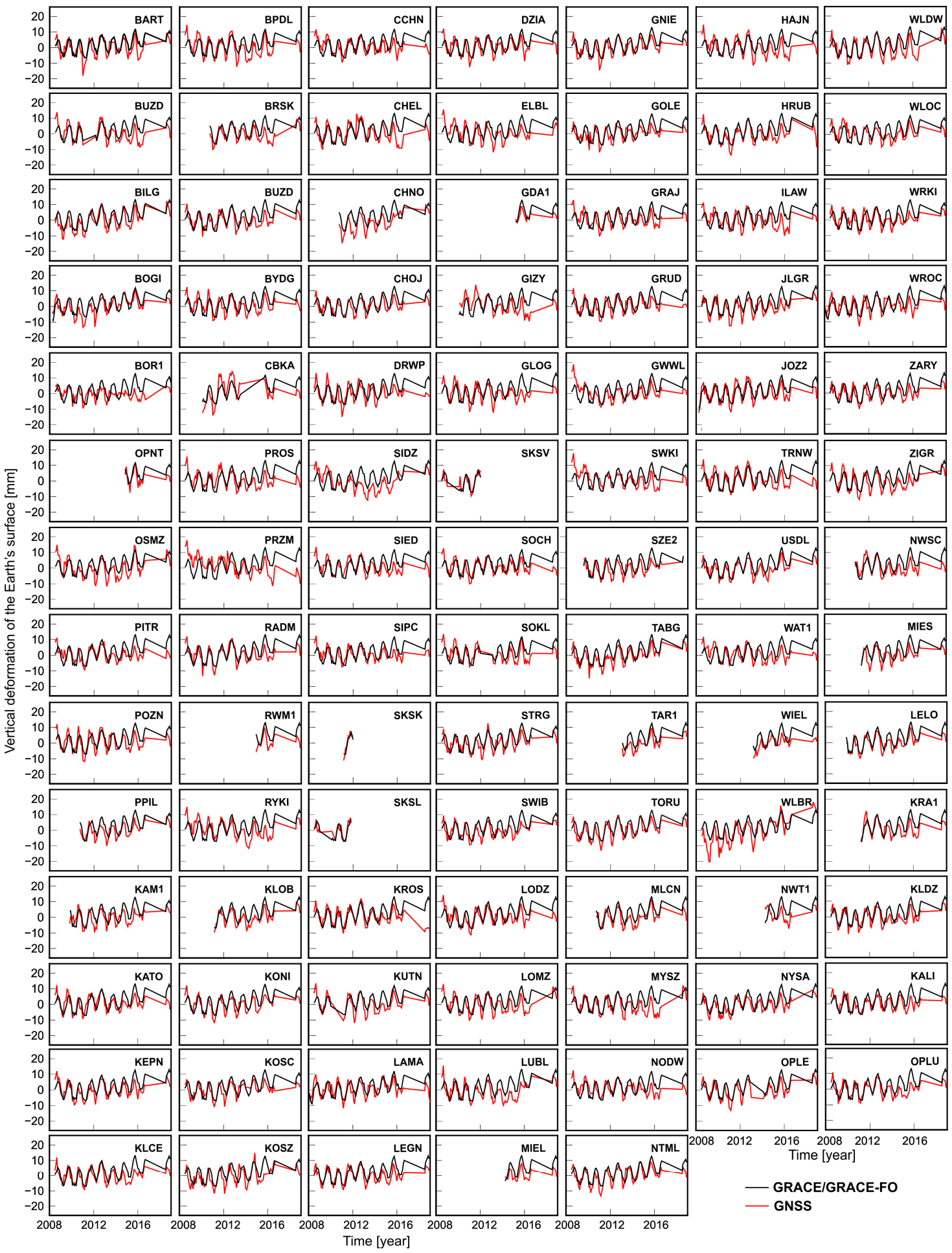

Figure 4. Time series of monthly vertical deformations of the Earth's surface determined from GNSS and GRACE/GRACE-FO satellite missions' data at the stations of the ASG-EUPOS network.

The results presented in Figure 4 exhibit a seasonal pattern over the area investigated. It is observed that maximum values of $\Delta h_{\mathrm{m} \text {-GNSS }}$ and $\Delta h_{\mathrm{m} \text {-GRACE }}$ Occur during the summer-fall seasons and minimum values during the winter-spring seasons [26]. This pattern can be attributed to the change in the mass loading caused by seasonal variations in the water mass with maximum values in March and minimum values in July-September $[26,60]$. For all GNSS stations investigated, the phase difference between $\Delta h_{\mathrm{m} \text {-GNSS }}$ and $\Delta h_{\mathrm{m} \text {-GRACE }}$ is less than one month, which can be considered negligible. Statistics 
of peak-to-peak variations of the seasonal pattern of the monthly vertical deformations are given in Table 1.

Table 1. Statistics of peak-to-peak variations of $\Delta h_{\mathrm{m}-\mathrm{GNSS}}$ and $\Delta h_{\mathrm{m}-\mathrm{GRACE}}[\mathrm{mm}]$.

\begin{tabular}{ccccc}
\hline $\boldsymbol{\Delta} \boldsymbol{h}$ & Min & Max & Median & Std \\
\hline $\boldsymbol{\Delta} \boldsymbol{h}_{\mathrm{m}-\mathrm{GNSS}}$ & 10.2 & 38.2 & 21.7 & 4.0 \\
$\boldsymbol{\Delta} \boldsymbol{h}_{\mathrm{m} \text {-GRACE }}$ & 13.8 & 21.4 & 20.0 & 1.6 \\
\hline
\end{tabular}

The results presented in Table 1 indicate that although the medians of peak-to-peak variations of the seasonal pattern in $\Delta h_{\mathrm{m} \text {-GNSS }}$ and $\Delta h_{\mathrm{m} \text {-GRACE }}$ are in a good agreement, the dispersion and the

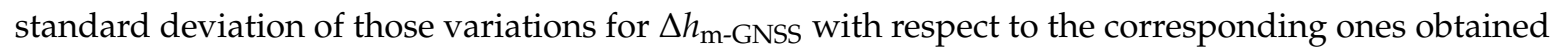
from $\Delta h_{\mathrm{m} \text {-GRACE }}$ are higher by a factor of approx. 3.5, and approx. 2.5, respectively. The higher

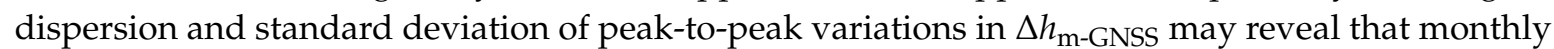
vertical deformations obtained from GNSS data include the local deformation signal which cannot be detected from GRACE/GRACE-FO satellite missions' data. The sources of such local deformation signal may be (i) thermoelastic deformation of the monuments caused by seasonal variation of the Earth's temperature [61] and (ii) poroelastic deformations caused by large variation of the water table [62]. Besides these geophysical sources, systematic errors in GNSS observations such as mismodeling of daily and subdaily tidal signals [63], presence of GPS draconitic signal $[37,64]$ as well as the variation in the phase center and the local multipath, can also induce the specific $\Delta h_{\mathrm{m} \text {-GNSS }}$ pattern for a station [65].

Furthermore, along with the seasonal pattern of $\Delta h$ obtained from GNSS and GRACE/GRACE-FO satellite missions data illustrated in Figure 4, there are also linear trends in the monthly vertical deformation of the Earth's surface (Figure 5). Statistics of these linear trends are given in Table 2. It should be mentioned that due to limited GNSS data at SKSL, SKSK and SKSV stations of the ASG-EUPOS network, linear trends of $\Delta h$ have not been estimated at these sites. The results presented in Figure 5 and Table 2 indicate positive linear trends for $\Delta h_{\mathrm{m}-\mathrm{GRACE}}$ at the ASG-EUPOS sites, ranging from $0.67 \mathrm{~mm} /$ year to $1.86 \mathrm{~mm} /$ year. These trends can be ascribed to the annual water depletion over the territory of Poland, observed beyond the extreme land hydrology events, i.e., flooding and increased precipitation, occurred in 2010-2011 (e.g., [66]). It should be noted that magnitudes of linear trends estimated from $\Delta h_{\mathrm{m}-\mathrm{GRACE}}$ depend on both the covering period and number of months used.

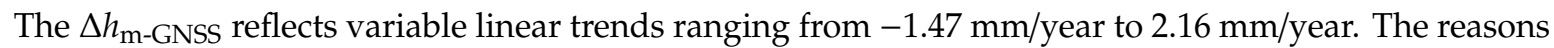
for these different linear trends can be attributed to the unstable monument [67], anthropogenic factors such as subsidence of mining areas and over exploitation of groundwater [68] and the presence of diverse geological structures such as Eastern European Precambrian platform, young western and middle Paleozoic platform as well as Carpathian region [69]. As the factors causing linear trends in $\Delta h_{\mathrm{m} \text {-GNSS }}$ and $\Delta h_{\mathrm{m} \text {-GRACE }}$ are different, the distinctive mismatch between linear trends of $\Delta h_{\mathrm{m}-\mathrm{GNSS}}$ and $\Delta h_{\mathrm{m} \text {-GRACE }}$ for some ASG-EUPOS GNSS stations such as PRZM, SWKI occurs. The linear trends in $\Delta h_{\mathrm{m} \text {-GRACE }}$ in the case of ASG-EUPOS GNSS stations PRZM, SWKI can primarily be attributed to the manifestation of the elastic response of the water depletion over the area. On the other hand,

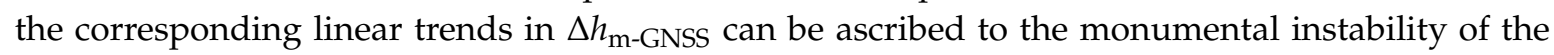
ASG-EUPOS GNSS station, anthropogenic activity and water mass change occurring in limited spatial scales, e.g., few kilometers, as well as the presence of geological features. The uncommon linear trends in $\Delta h_{\mathrm{m} \text {-GNSS }}$ and $\Delta h_{\mathrm{m} \text {-GRACE }}$ may result in disagreements between vertical deformations of the Earth's surface determined from GNSS and GRACE/GRACE-FO satellite missions' data. Time series of $\Delta h_{\mathrm{m}-\mathrm{GNSS}}$ and $\Delta h_{\mathrm{m}-\mathrm{GRACE}}$ were thus detrended for further analysis. 


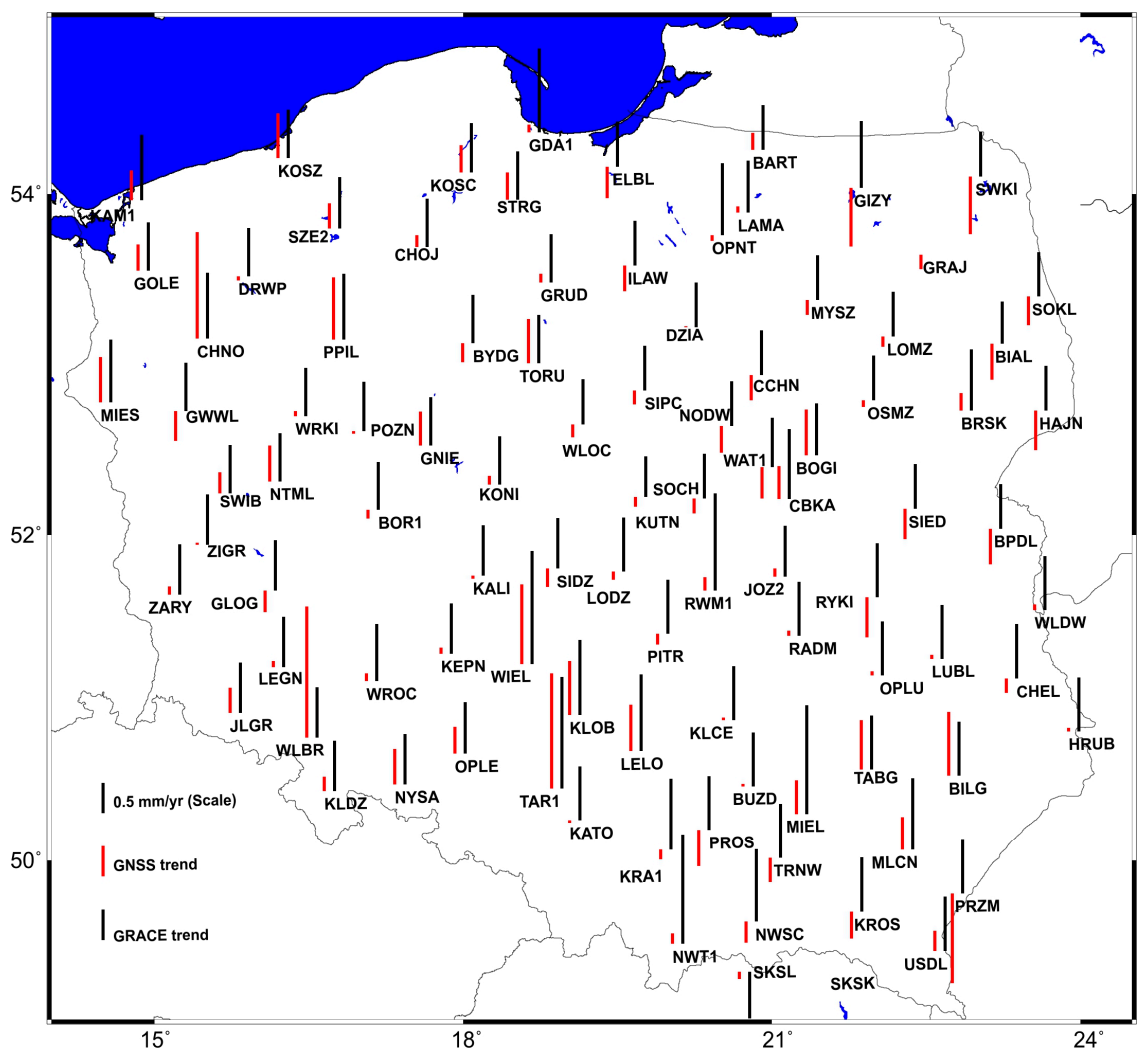

Figure 5. Linear trends of vertical deformation of the Earth's surface estimated at ASG-EUPOS sites using GRACE/GRACE-FO satellite missions and GNSS data.

Table 2. Statistics of linear trends of vertical deformation of the Earth's surface estimated at ASG-EUPOS sites (except sites SKSL, SKSK and SKSV) using GRACE/GRACE-FO satellite missions and GNSS data [mm/year].

\begin{tabular}{ccccc}
\hline$\Delta h$ & Min & Max & Median & Std \\
\hline$\Delta h_{\text {m-GNSS }}$ & -1.47 & 2.16 & 0.07 & 0.58 \\
$\Delta h_{\text {m-GRACE }}$ & 0.67 & 1.86 & 0.83 & 0.25 \\
\hline
\end{tabular}

In order to compare monthly vertical deformations of the Earth's surface $\Delta h$ determined from GNSS and GRACE/GRACE-FO satellite missions' data, correlations and standard deviations of the differences between (1) $\Delta h_{\mathrm{m} \text {-GNSS }}$ and $\Delta h_{\mathrm{m} \text {-GRACE, }}$ and (2) detrended $\Delta h_{\mathrm{m} \text {-GNSS }}$ and detrended $\Delta h_{\mathrm{m} \text {-GRACE }}$ were computed. Figure 6 depicts coefficients of correlations between $\Delta h$ obtained from GNSS data and the corresponding ones obtained from GRACE/GRACE-FO satellite missions' data at the locations of the ASG-EUPOS stations investigated. Statistics of these correlation coefficients are given in Table 3. The results presented in Figure 6 and Table 3 reveal that at $68 \%$ of the ASG-EUPOS GNSS stations investigated, strong correlations (correlation coefficients ranging from 0.60 to 0.90 ) between $\Delta h_{\mathrm{m} \text {-GNSS }}$ and $\Delta h_{\mathrm{m} \text {-GRACE }}$ were obtained. Moderate/weak correlations (correlation coefficients ranging from

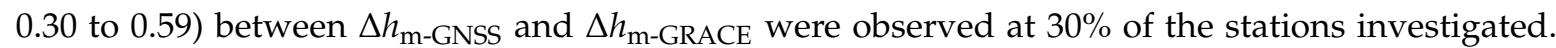

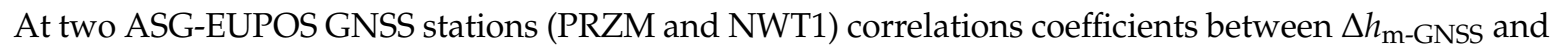
$\Delta h_{\mathrm{m} \text {-GRACE }}$ were found to be 0.13 and 0.29 , respectively. After detrending $\Delta h_{\mathrm{m} \text {-GNSS }}$ and $\Delta h_{\mathrm{m} \text {-GRACE }}$ strong correlations between $\Delta h_{\mathrm{m} \text {-GNSS }}$ and $\Delta h_{\mathrm{m} \text {-GRACE }}$ were obtained at $93 \%$ of the GNSS stations investigated. At $7 \%$ of the stations, moderate/weak correlations between $\Delta h_{\mathrm{m} \text {-GNSS }}$ and $\Delta h_{\mathrm{m} \text {-GRACE }}$ were obtained. Thus, values of correlations coefficients have clearly improved after detrending. For the ASG-EUPOS stations PRZM the value of the correlation coefficient increased to 0.71 after the removal of linear trends from $\Delta h_{\mathrm{m}-\mathrm{GNSS}}$ and $\Delta h_{\mathrm{m} \text {-GRACE }}$ (cf. Figures 4 and 5). On the contrary the value of 
the correlation coefficient at the station NWT1 does not change much despite removing the linear trend. However, it should be noted that the value of the coefficient of correlation between $\Delta h_{\mathrm{m}-\mathrm{GNSS}}$ and $\Delta h_{\mathrm{m}-\mathrm{GRACE}}$ in the case of NWT1 can be less reliable because of the shorter time span and gaps in $\Delta h$ time series. Overall, the results presented in Figure 6 show strong correlations between $\Delta h$ obtained from GNSS data and corresponding ones determined using GRACE/GRACE-FO data. Strong correlations between $\Delta h$ suggest that surface mass loading effects are the dominant contributor to the vertical deformation of the Earth's surface over the area investigated and also indicate consistency of the GNSS and GRACE/GRACE-FO satellite missions' data in monitoring surface mass loading effects. The cases of weak correlations between $\Delta h$ obtained from GNSS data and the corresponding ones determined using GRACE/GRACE-FO satellite missions' data may be attributed to variety of reasons such as local temporal variations of water masses and GNSS station dependent errors. However, in this study the values of correlation coefficients got improved after removing the linear trends and there are only two ASG-EUPOS stations (NWT1 and WIEL) for which values remain under 0.5. The case of NWT1 has already been stated above, and regarding WIEL the authors believe that the value of the correlation coefficient may get improved with the use of the longer data span.

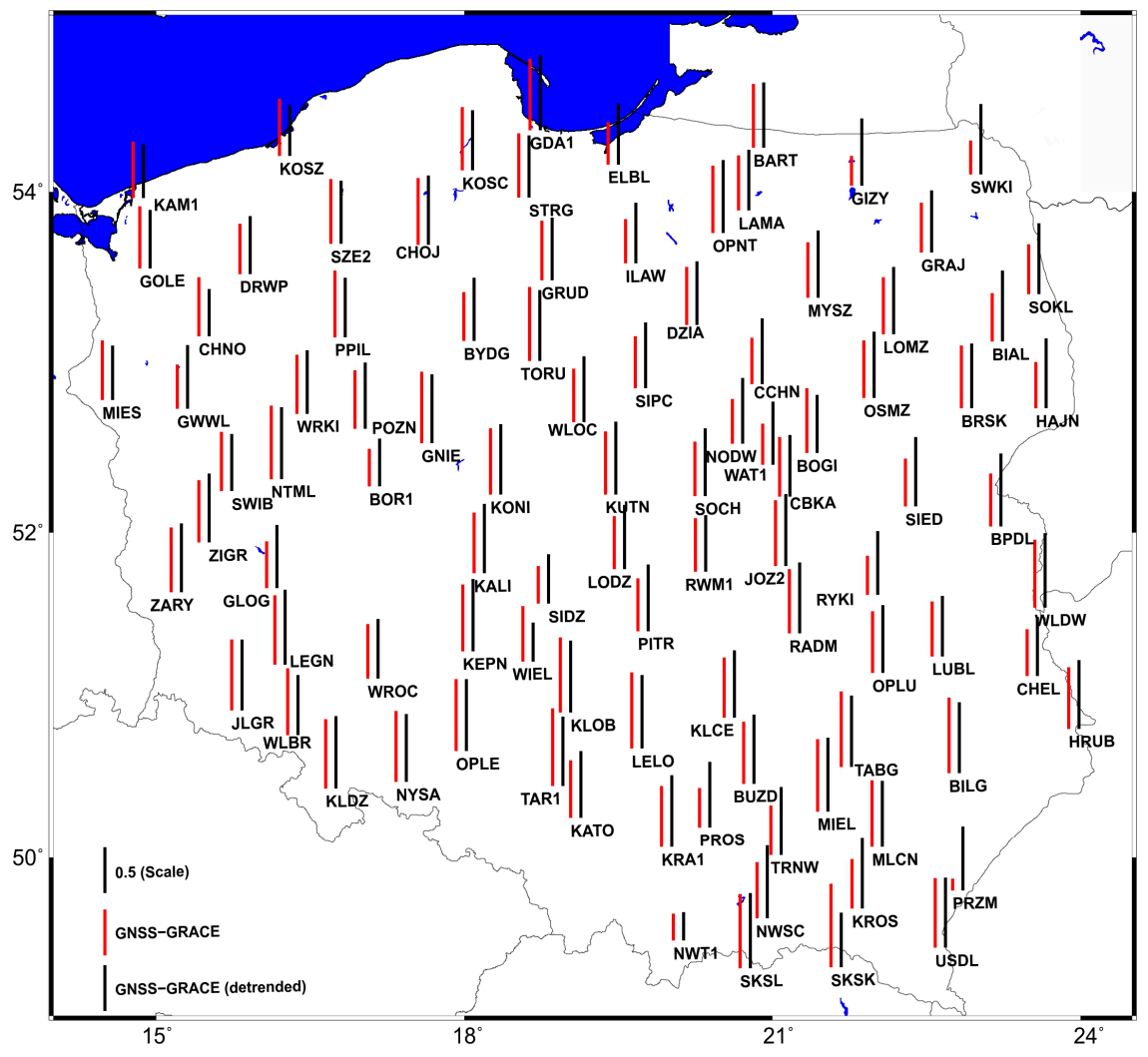

Figure 6. Coefficients of correlation between vertical deformations of the Earth's surface determined from ASG-EUPOS and GRACE/GRACE-FO satellite missions' data.

Table 3. Statistics of correlation coefficient values presented in Figure 6.

\begin{tabular}{cccc}
\hline $\boldsymbol{\Delta} \boldsymbol{h}$ & Min & Max & Mean \\
\hline GNSS-GRACE & 0.13 & 0.91 & 0.64 \\
GNSS-GRACE (detrended) & 0.31 & 0.83 & 0.72 \\
\hline
\end{tabular}

The standard deviations of the differences between $\Delta h$ obtained from GNSS data and the corresponding ones obtained from GRACE/GRACE-FO satellite missions' data were illustrated in Figure 7. Statistics of these standard deviations are given in Table 4 . They reveal that the mean value 
of standard deviations of the differences between $\Delta h_{\mathrm{m} \text {-GNSS }}$ and $\Delta h_{\mathrm{m} \text {-GRACE }}$ decreased by ca. $18 \%$ (i.e., from 4.2 to $3.4 \mathrm{~mm}$ ) after removing the linear trend of $\Delta h$ specified in Figure 5. The reduced value of standard deviations of $\Delta h$ differences after removing linear trend in $\Delta h$ signifies the reduction of amplitude discrepancy between detrended $\Delta h_{\mathrm{m} \text {-GNSS }}$ and detrended $\Delta h_{\mathrm{m} \text {-GRACE }}$ in relation to that of $\Delta h_{\mathrm{m} \text {-GNSS }}$ and $\Delta h_{\mathrm{m} \text {-GRACE. }}$ Overall, the improvement, in terms of correlation coefficients (Figure 6) and standard deviations of the $\Delta h$ differences (Figure 7), obtained after removing linear trends in $\Delta h$ is observed. The results also indicate that although $\Delta h$ obtained from GNSS and GRACE/GRACE-FO data agree well, linear trends in $\Delta h$ can vary significantly. Therefore, detrended $\Delta h_{\mathrm{m} \text {-GNSS }}$ are further used for estimating $\triangle E W T$.

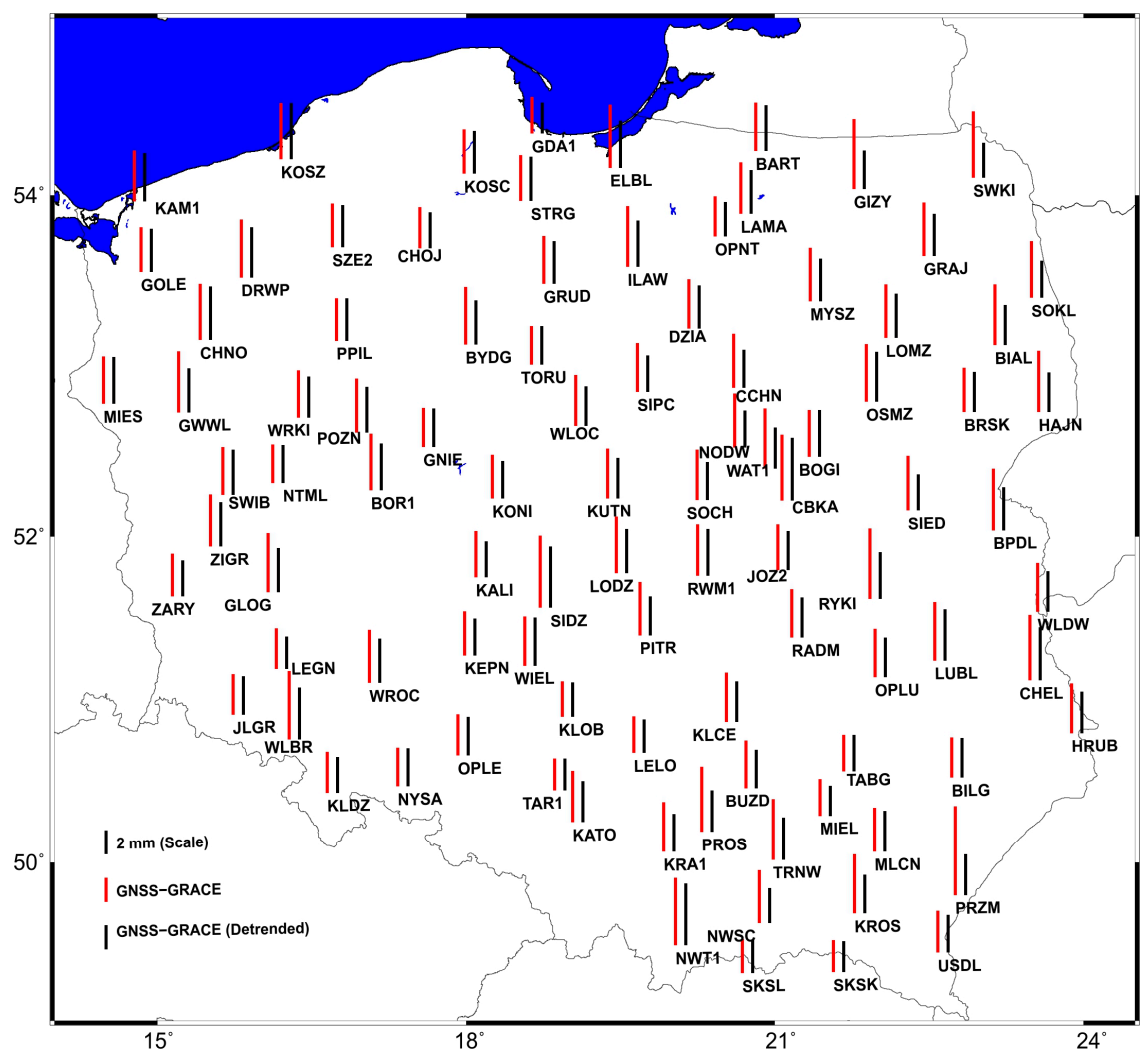

Figure 7. Standard deviations of the differences between vertical deformations of the Earth's surface determined from ASG-EUPOS and GRACE/GRACE-FO satellite missions' data.

Table 4. Statistics of standard deviation values presented in Figure 7 [mm].

\begin{tabular}{cccc}
\hline$\Delta h$ & Min & Max & Mean \\
\hline GNSS-GRACE & 2.6 & 7.3 & 4.2 \\
GNSS-GRACE (detrended) & 2.5 & 5.2 & 3.4 \\
\hline
\end{tabular}

\subsection{Monthly Variations of Equivalent Water Thickness}

Monthly variations of equivalent water thickness $\triangle E W T_{\mathrm{m} \text {-GRACE }}$ and $\triangle E W T_{\mathrm{m} \text {-GNSS }}$ were determined with the use of Equations (2) and (4) as well as data from GRACE/GRACE-FO satellite missions and GNSS data from the ASG-EUPOS CORS network, respectively. Moreover, monthly variations of equivalent water thickness $\triangle E W T_{\mathrm{m}-W G H M}$ were obtained from the WGHM. In order to be consistent with the detrended $\triangle E W T_{\mathrm{m}-\mathrm{GNSS}}$, linear trends in $\triangle E W T_{\mathrm{m} \text {-GRACE }}$ and $\Delta E W T_{\mathrm{m} \text {-WGHM }}$ were also removed. Then, combined solutions $\triangle E W T_{\mathrm{m} \text {-Combsol }}$ were determined using Equation (5) with the weights $w_{\mathrm{GNSS}}$ and $w_{\mathrm{GRACE}}$ estimated by Equation (4) and $\triangle E W T$ determined from GRACE/GRACE-FO and GNSS data. The ratio between these weights (i.e., $w_{\mathrm{GNSS}}: w_{\mathrm{GRACE}}$ ) is illustrated in Figure 8. 
The maximum (i.e., 0.73) and minimum (i.e., 0.14) values of this ratio were observed at the GNSS stations CHOJ and SIDZ, respectively. For ca. 72\% of GNSS stations investigated (i.e., 69 GNSS stations of ASG-EUPOS network), the ratio between $w_{\mathrm{GNSS}}$ and $w_{\mathrm{GRACE}}$ is at the level of $0.46 \pm 0.13$. Time series of $\triangle E W T_{\mathrm{m} \text {-GRACE }}, \Delta E W T_{\mathrm{m} \text {-GNSS }}$ and $\triangle E W T_{\mathrm{m} \text {-CombSol }}$ as well as the corresponding $\Delta E W T_{\mathrm{m}-W G H M}$ obtained from the WGHM are illustrated in Figure 9. It is observed from the results presented in Figure 9 that likewise $\Delta h$, there is also a seasonal pattern in $\Delta E W T$. This seasonal pattern can be attributed to seasonal mass variations related with the hydrological cycle over the territory of Poland. Statistics of peak-to-peak variations of the seasonal pattern of the monthly equivalent water thickness variations are given in Table 5. From the values of medians and standard deviations, it is clear that overall $\Delta E W T_{\mathrm{m} \text {-CombSol }}$ are in better agreement with $\Delta E W T_{\mathrm{m} \text {-WGHM }}$ than those of $\Delta E W T_{\mathrm{m} \text {-GNSS }}$ and $\triangle E W T_{\mathrm{m}-\mathrm{GRACE}}$.

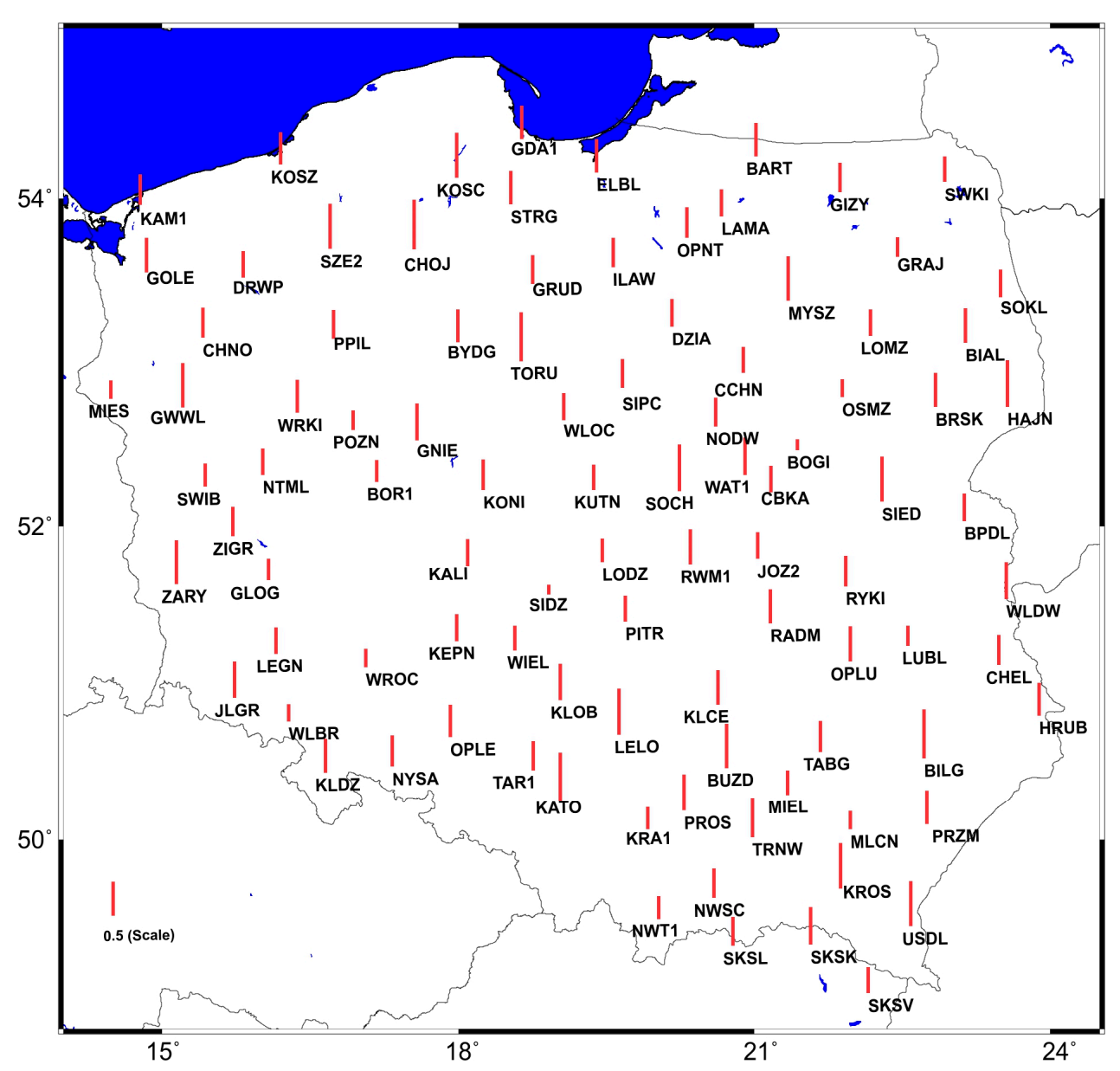

Figure 8. The ratio between the weights $w_{\mathrm{GNSS}}$ and $w_{\mathrm{GRACE}}$ (i.e., $w_{\mathrm{GNSS}}: w_{\mathrm{GRACE}}$ ). 


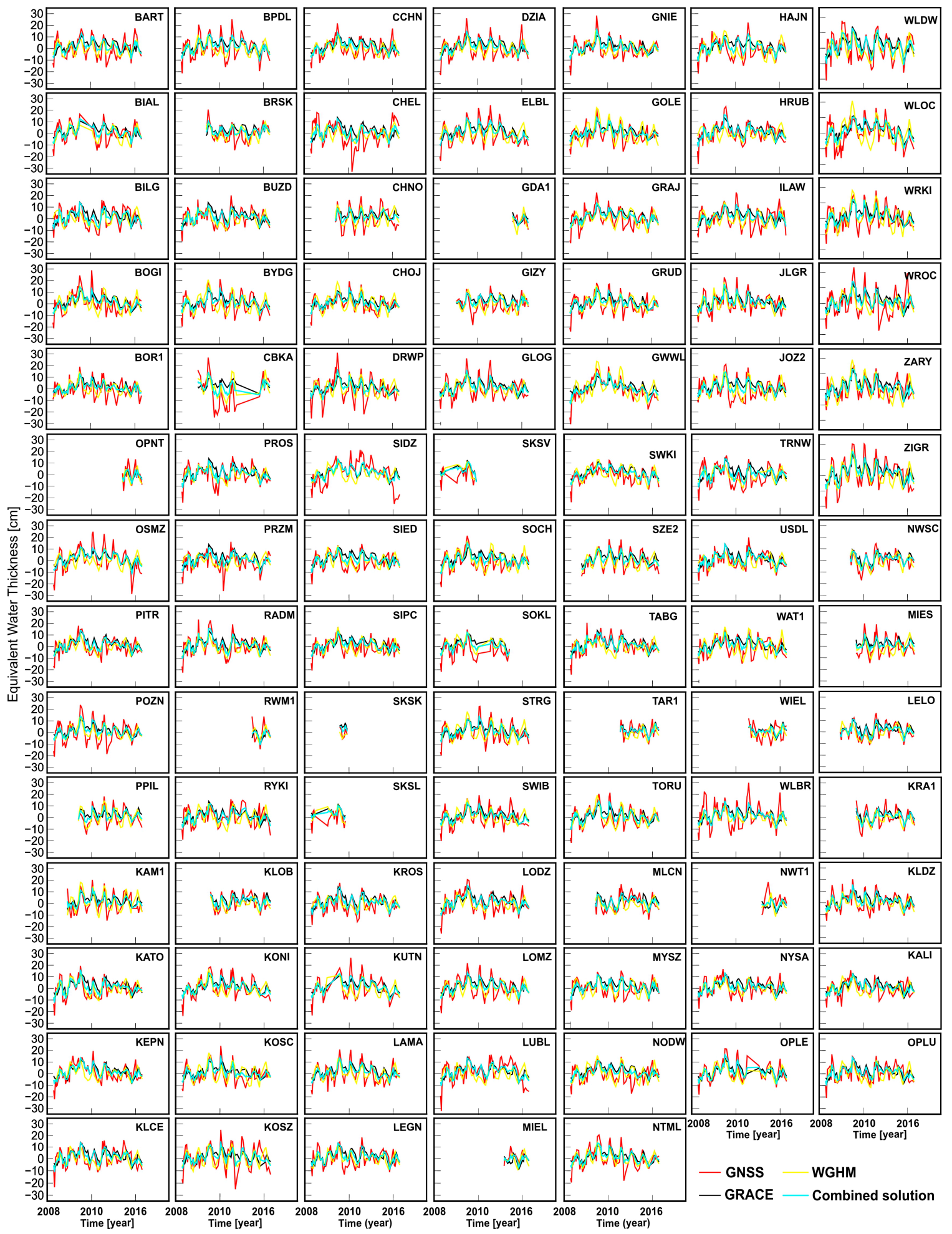

Figure 9. Time series of monthly temporal variations of the equivalent water thickness $\triangle E W T$ determined from GNSS data $\triangle E W T_{\mathrm{m}-G N S S}$, GRACE satellite mission data $\triangle E W T_{\mathrm{m}-\mathrm{GRACE}}$ and their combined solutions $\triangle E W T_{\mathrm{m}-\mathrm{CombSol}}$ as well as the corresponding $\Delta E W T_{\mathrm{m}-W G H M}$ obtained from the WGHM. 
Table 5. Statistics of peak-to-peak variations of $\triangle E W T_{\mathrm{m}-\mathrm{GNSS}}, \Delta E W T_{\mathrm{m}-\mathrm{GRACE}}, \Delta E W T_{\mathrm{m}-\mathrm{CombSol}}$ and $\triangle E W T_{\mathrm{m}-W G H M}[\mathrm{~cm}]$.

\begin{tabular}{|c|c|c|c|c|}
\hline$\Delta E W T$ & Min & $\operatorname{Max}$ & Median & Std \\
\hline$\Delta E W T_{\mathrm{m}-\mathrm{GNSS}}$ & 11.1 & 56.9 & 38.5 & 8.5 \\
\hline$\Delta E W T_{\mathrm{m}-\mathrm{GRACE}}$ & 11.1 & 22.2 & 18.7 & 3.2 \\
\hline$\Delta E W T_{\mathrm{m}-\mathrm{CombSol}}$ & 6.7 & 28.4 & 22.2 & 4.3 \\
\hline$\Delta E W T_{\mathrm{m}-\mathrm{WGHM}}$ & 5.7 & 37.1 & 21.4 & 4.9 \\
\hline
\end{tabular}

In order to assess the performance of GNSS data from ASG-EUPOS CORS network for the determination of $\triangle E W T$ as well as for improving $\triangle E W T$ determined from GRACE/GRACE-FO satellite missions' data, correlations between (1) $\triangle E W T_{\mathrm{m} \text {-GNSS }}$ and $\triangle E W T_{\mathrm{WGHM}}$, (2) $\Delta E W T_{\mathrm{m} \text {-GRACE }}$ and $\triangle E W T_{\mathrm{m}-W G H M}$, and (3) $\Delta E W T_{\mathrm{m}-\mathrm{CombSol}}$ and $\triangle E W T_{\mathrm{m}-W G H M}$ have been estimated (Figure 10 and Table 6). Strong correlations (correlation coefficients ranging from 0.60 to 0.70 ), between $\triangle E W T_{\mathrm{m} \text {-GNSS }}$ and $\triangle E W T_{\mathrm{m}-W G H M}$ were obtained at $32 \%$ of GNSS sites investigated; moderate/weak correlations (correlation coefficients ranging from 0.30 to 0.59 ), were obtained at $56 \%$ of the GNSS sites investigated; at about $12 \%$ of GNSS sites investigated, no correlations (correlation coefficient ranging from -0.41 to 0.29 ) have been obtained. In terms of correlations between $\Delta E W T_{\mathrm{m} \text {-GRACE }}$ and $\triangle E W T_{\mathrm{m}-W G H M}$, strong correlations (correlation coefficients ranging from 0.60 to 0.79 ) have been obtained at $57 \%$ of the stations investigated; moderate/weak correlations (correlation coefficients ranging from 0.30 to 0.59 ) were obtained in the case of $38 \%$ of the stations investigated; at the remaining $5 \%$ of the GNSS sites investigated correlation coefficients range from -0.04 to 0.29 . It is clear that the obtained correlations between $\triangle E W T_{\mathrm{m} \text {-GRACE }}$ and $\triangle E W T_{\mathrm{m} \text {-WGHM }}$ are much stronger than the corresponding ones between $\Delta E W T_{\mathrm{m} \text {-GNSS }}$ and $\triangle E W T_{\mathrm{m}-W G H M}$. The reason for this may be ascribed to the fact that $\triangle E W T_{\mathrm{m} \text {-GRACE }}$ is obtained directly from the monitoring of the gravitational effect of mass variations within the Earth's system, while $\triangle E W T_{\mathrm{m} \text {-GNSS }}$ is determined by inverting the response of the Earth's surface to the mass variation at a point. The response of the Earth's surface to the mass variation depends upon the underlying crustal properties. Moreover, $\triangle E W T_{\mathrm{m}-\mathrm{GNSS}}$ is sensitive to the local signal and the presence of

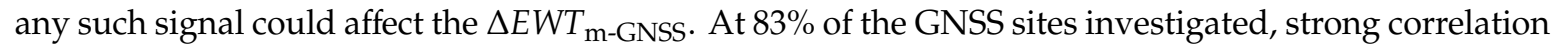
(correlation coefficients from 0.60 to 0.80 ) between $\triangle E W T_{\mathrm{m}-\mathrm{CombSol}_{1}}$ and $\Delta E W T_{\mathrm{m}-W G H M}$ were obtained. At $16 \%$ of the GNSS stations investigated, the correlations are moderate/weak. For the remaining $1 \%$ of the GNSS stations investigated (one station) the correlation coefficient is 0.27 . The values of coefficients of correlation between $\Delta E W T_{\mathrm{m}-\mathrm{CombSol}}$ and $\Delta E W T_{\mathrm{m}-W G H M}$ have evidently been improved at $85 \%$ of the GNSS stations in comparison to values of coefficients of correlation between $\triangle E W T_{\mathrm{m} \text {-GRACE }}$ and $\triangle E W T_{\mathrm{m}-W G H M}$. Furthermore, combining $\triangle E W T$ obtained from GNSS data with the corresponding ones determined from GRACE/GRACE-FO satellite missions' data does not change, however, the correlation coefficients' values at $3 \%$ of the GNSS stations investigated. At $12 \%$ of the GNSS stations, the addition of GNSS data worsen the $\triangle E W T$ in terms of correlations with the $\triangle E W T_{\mathrm{m}-W G H M}$. The good agreement, in terms of correlations, between $\triangle E W T_{\mathrm{m}-\mathrm{CombSol}}$ and $\triangle E W T_{\mathrm{m}-W G H M}$, indicates that GNSS data from CORS network stations provides in general valuable information to improve GRACE/GRACE-FO solutions for monitoring mass variation within the Earth's system. 


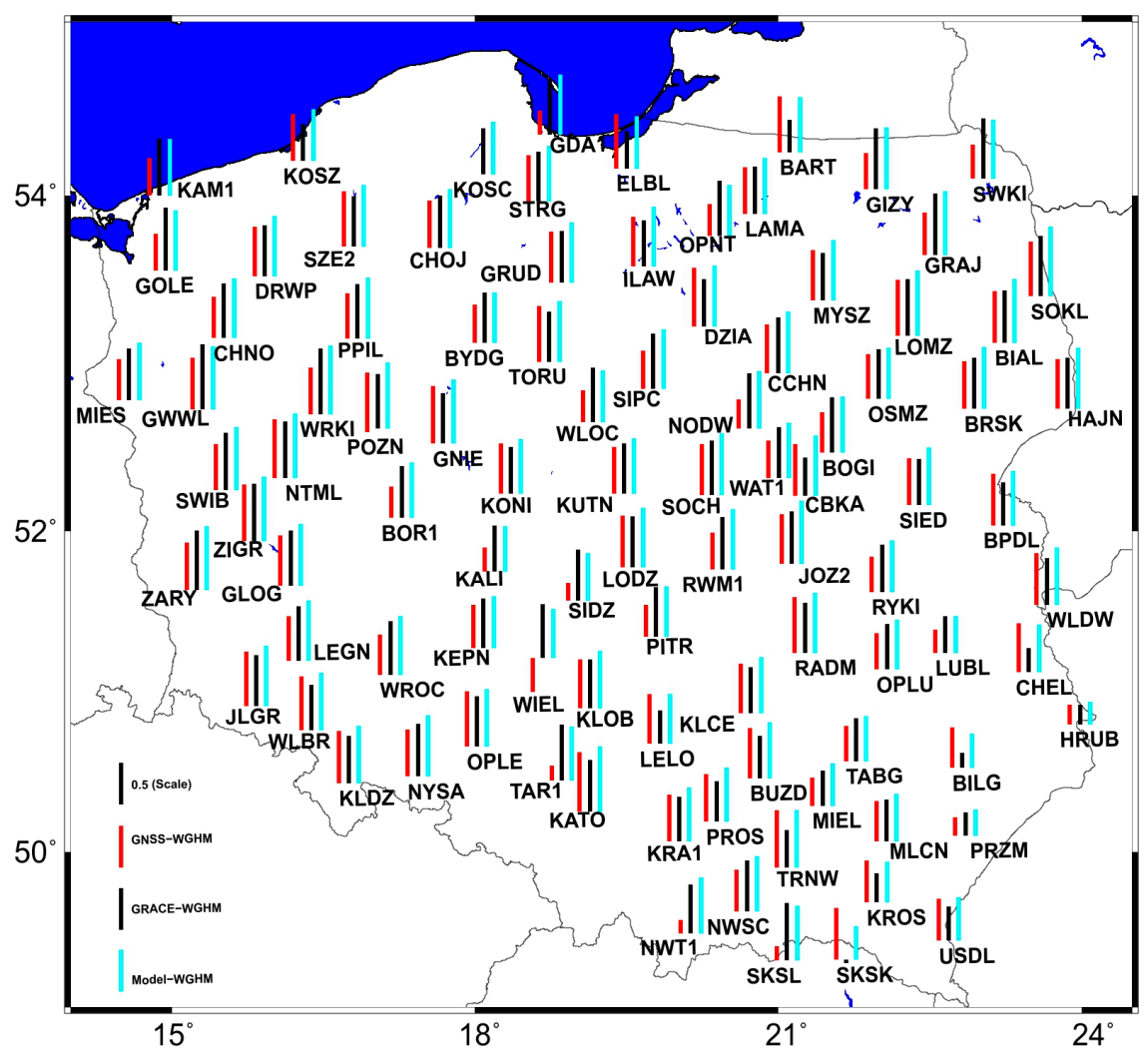

Figure 10. Coefficients of correlation between $\triangle E W T_{\mathrm{m}-\mathrm{GNSS}}$ and $\triangle E W T_{\mathrm{m}-W G H M}$ (red bar), between $\triangle E W T_{\mathrm{m}-G R A C E}$ and $\triangle E W T_{\mathrm{m}-W G H M}$ (black bar), and between $\triangle E W T_{\mathrm{m}-C_{\text {CombSol }}}$ and $\Delta E W T_{\mathrm{m}-W G H M}$ (cyan bar).

Table 6. Statistics of correlation coefficient values presented in Figure 10.

\begin{tabular}{cccc}
\hline $\boldsymbol{\Delta E W T}$ & Min & Max & Mean \\
\hline GNSS & -0.41 & 0.71 & 0.51 \\
GRACE & -0.04 & 0.79 & 0.58 \\
Combined solution & 0.27 & 0.83 & 0.67 \\
\hline
\end{tabular}

With the use of Equation (7), the differences $\delta \Delta E W T_{\mathrm{m}-\mathrm{GNSS}}, \delta \Delta E W T_{\mathrm{m}-\mathrm{GRACE}}$ and $\delta \Delta E W T_{\mathrm{m} \text {-CombSol }}$ were determined. Standard deviations of these differences were depicted in Figure 11. Statistics of these standard deviations are given in Table 7. The results presented in Figure 11 and Table 7 reveal that the mean values of standard deviations of differences $\delta \Delta E W T_{\mathrm{m}-\mathrm{GNSS}}, \delta \Delta E W T_{\mathrm{m} \text {-GRACE }}$ and $\delta \Delta E W T_{\mathrm{m}-\mathrm{CombSol}}$ are $7 \mathrm{~cm}, 5 \mathrm{~cm}$ and $4 \mathrm{~cm}$, respectively. The values of standard deviations of $\delta \Delta E W T_{\mathrm{m}-\mathrm{CombSol}}$ decreased at 44 sites of the ASG-EUPOS CORS network in comparison to standard deviations of $\delta \triangle E W T_{\mathrm{m}-G R A C E}$.

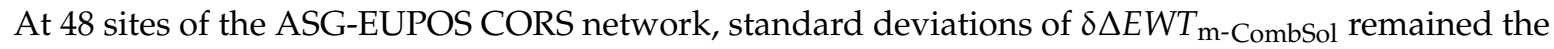
same as the values of standard deviations of $\delta \triangle E W T_{\mathrm{m}-G R A C E}$. There are only 4 sites of the ASG-EUPOS CORS network where standard deviations of $\delta \Delta E W T_{\mathrm{m}-\mathrm{CombSol}}$ increased in comparison to that of the $\delta \triangle E W T_{\mathrm{m}-\mathrm{GRACE}}$. Although there are improvements in the median values of standard deviations of $\delta \Delta E W T_{\mathrm{m}-\mathrm{CombSol}}$ in comparison to the corresponding ones of $\delta \Delta E W T_{\mathrm{m} \text {-GRACE}}$, they are limited to only $46 \%$ of GNSS sites investigated. This can be attributed to the amplitude differences, due the fact that GNSS data present $\triangle E W T$ at points, while GRACE/GRACE-FO satellite mission data and the WGHM present $\triangle E W T$ over an area. Furthermore, amplitude differences between $\triangle E W T_{\text {m-GRACE }}$

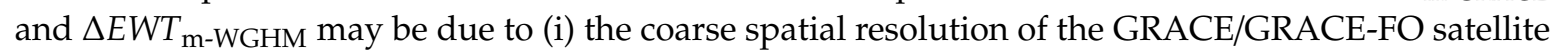
missions data (ca. $3^{\circ} \times 3^{\circ}$ at the equator), and (ii) the spatial resolution of the WGHM (ca. $0.5^{\circ} \times 0.5^{\circ}$ ), as well as uncertainties of the WGHM related to modeling of storage capacity, fluxes, and human 
intervention [70]. As the data from GNSS, GRACE/GRACE-FO satellite missions and the WGHM characterize with differences between each other, so incorporation of $\triangle E W T_{\mathrm{m} \text {-GNSS }}$ to $\triangle E W T_{\mathrm{m}-\mathrm{GRACE}}$

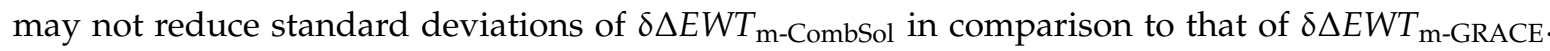
Since, there are only 4 GNSS stations where the addition of $\triangle E W T_{\mathrm{m} \text {-GNSS }}$ to $\triangle E W T_{\mathrm{m} \text {-GRACE }}$ increase the standard deviation values of $\delta \Delta E W T_{\mathrm{m}-C o m b S o l}$, addition of $\Delta E W T_{\mathrm{m}-\mathrm{GNSS}}$ to $\Delta E W T_{\mathrm{m}-\mathrm{GRACE}}$, in general, either reduced or did not change the values of standard deviations in comparison to the corresponding ones of $\delta \triangle E W T_{\mathrm{m} \text {-GRACE. }}$

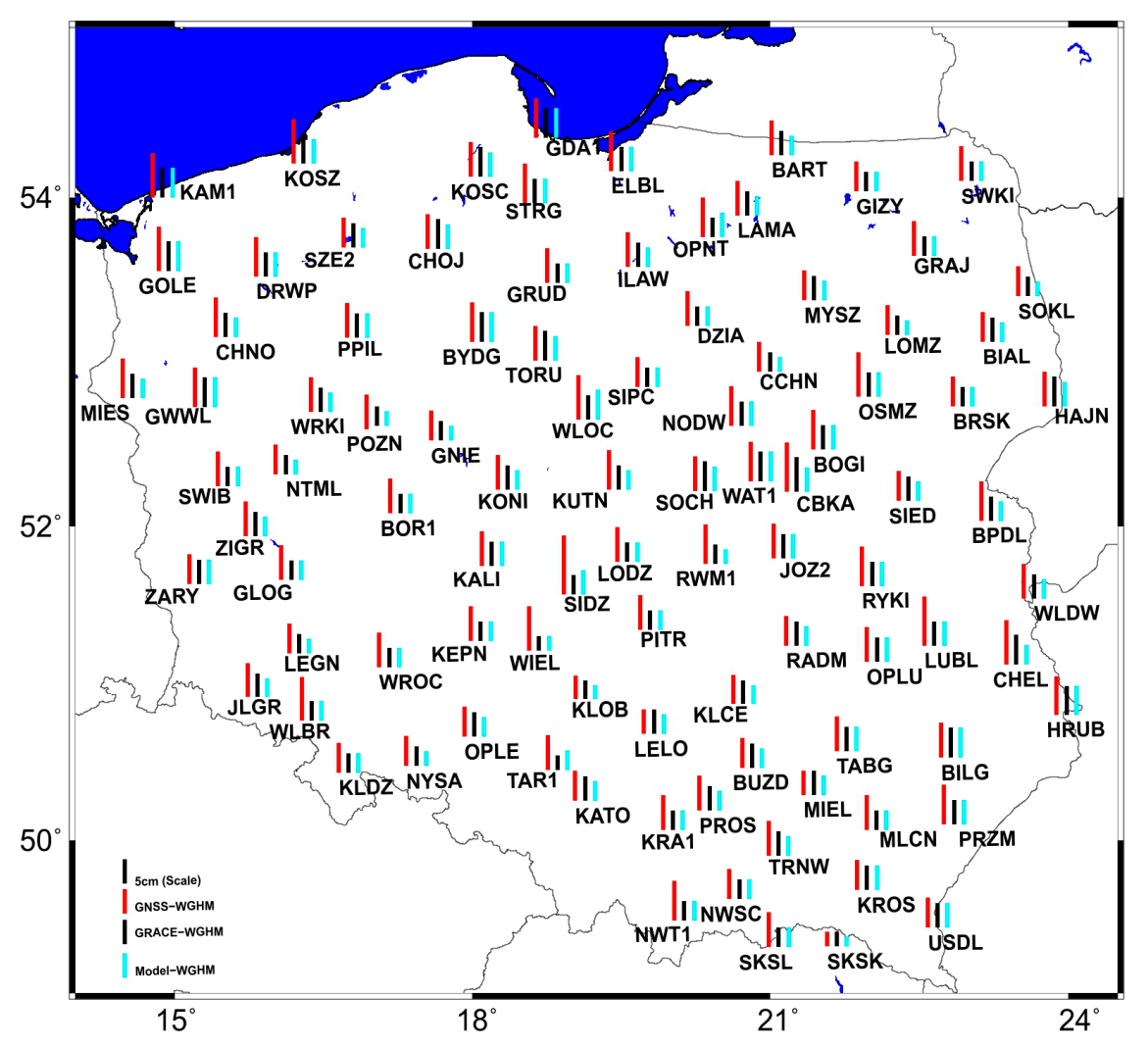

Figure 11. Standard deviations of differences $\delta \Delta E W T_{\mathrm{m} \text {-GNSS }}$ (red bar), $\delta \Delta E W T_{\mathrm{m}-\mathrm{GRACE}}$ (blue bar) and $\delta \triangle E W T_{\mathrm{m}-\mathrm{CombSol}}$ (cyan bar).

Table 7. Statistics of standard deviation values presented in Figure 11 [m].

\begin{tabular}{cccc}
\hline $\boldsymbol{\Delta} \boldsymbol{E W T}$ & Min & Max & Mean \\
\hline GNSS & 0.03 & 0.12 & 0.07 \\
GRACE & 0.03 & 0.07 & 0.05 \\
Combined solution & 0.02 & 0.06 & 0.04 \\
\hline
\end{tabular}

\section{Conclusions and Discussions}

In this study, monthly vertical deformations of the Earth's surface $\Delta h$ as well as temporal variations of equivalent water thickness $\triangle E W T$ were determined using GNSS data from the ASG-EUPOS CORS network as well as the CSR RL06 GRACE/GRACE-FO-based GGMs over the area of Poland. Combined solutions of $\triangle E W T$ were developed by combining $\triangle E W T$ obtained from GNSS data and the corresponding ones determined from GRACE satellite mission data. The $\triangle E W T$ obtained from GNSS data, GRACE/GRACE-FO satellite missions' data and from the determined combined solutions of $\triangle E W T$ were evaluated using the corresponding values obtained from the WGHM hydrological model. The main findings reveal: 
Over the area investigated, the seasonal patterns in $\Delta h$ determined from GNSS data of the

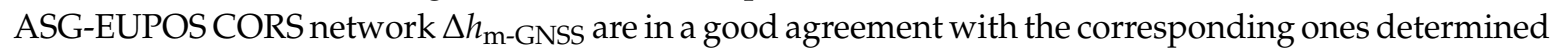

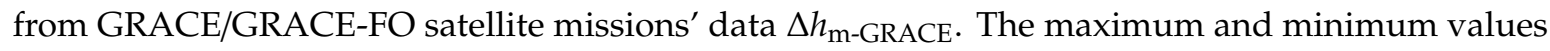
of $\Delta h$ occur during the summer-fall and winter-spring seasons, respectively. Linear trends in the time series of $\Delta h_{\mathrm{m} \text {-GNSS }}$ and $\Delta h_{\mathrm{m} \text {-GRACE }}$ are, however, not fully consistent. It is found that $\Delta h_{\mathrm{m} \text {-GRACE }}$ show positive linear trends which can be related with water depletion over the territory of Poland.

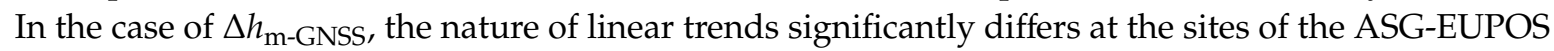

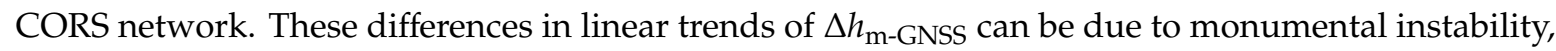
anthropogenic activity, and geological features. Strong correlations between $\Delta h_{\mathrm{m} \text {-GNSS }}$ and $\Delta h_{\mathrm{m} \text {-GRACE }}$ were obtained at $68 \%$ of GNSS sites investigated. When removing the linear trends in $\Delta h_{\mathrm{m}-\mathrm{GNSS}}$

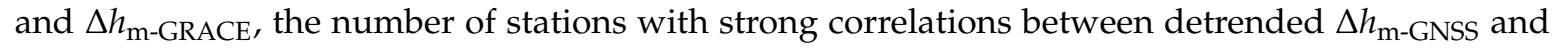
detrended $\Delta h_{\text {m-GRACE }}$ increased to $93 \%$ of GNSS sites investigated. Median values of standard deviations of differences between $\Delta h_{\mathrm{m} \text {-GNSS }}$ and $\Delta h_{\mathrm{m} \text {-GRACE }}$ as well as between detrended $\Delta h_{\mathrm{m} \text {-GNSS }}$ and detrended $\Delta h_{\mathrm{m} \text {-GRACE }}$ are $4.1 \mathrm{~mm}$ and $3.4 \mathrm{~mm}$, respectively. Overall, removing the linear trends in $\Delta h_{\mathrm{m} \text {-GNSS }}$ and $\Delta h_{\mathrm{m} \text {-GRACE }}$ results in clear improvements of the fit, in terms of both correlations and standard deviations of the difference between $\Delta h$ determined from GNSS data of the ASG-EUPOS CORS network to the corresponding ones determined from GRACE/GRACE-FO satellite mission data.

Furthermore, $\triangle E W T$ determined from GRACE/GRACE-FO satellite missions' data ( $\triangle E W T_{\mathrm{m} \text {-GRACE }}$ ) and from GNSS data of the ASG-EUPOS CORS network ( $\left.\triangle E W T_{\mathrm{m}-\mathrm{GNSS}}\right)$ as well as their combined solutions $\triangle E W T_{\mathrm{m}-\mathrm{CombSol}}$ are also in a good agreement with the $\Delta E W T_{\mathrm{m}-W G H M}$ obtained from the hydrological model WGHM. Strong correlations between (1) $\triangle E W T_{\mathrm{m} \text {-GNSS }}$ and $\triangle E W T_{\mathrm{m}-W G H M}$, (2) $\triangle E W T_{\mathrm{m} \text {-GRACE }}$ and $\Delta E W T_{\mathrm{m}-W G H M}$, as well as (3) $\Delta E W T_{\mathrm{m} \text {-CombSol }}$ and $\Delta E W T_{\mathrm{m} \text {-WGHM }}$ were obtained at $32 \%, 57 \%$ and $83 \%$ of the GNSS sites investigated, respectively. It has been found that the combination of $\triangle E W T_{\mathrm{m} \text {-GNSS }}$ and $\triangle E W T_{\mathrm{m} \text {-GRACE }}$ improves the determination of $\triangle E W T$, in terms of correlations coefficients, at $85 \%$ of GNSS sites investigated in comparison to the one obtained with the use of GRACE/GRACE-FO satellite missions' data only. The median values of standard deviations of differences $\Delta E W T_{\mathrm{m} \text {-GNSS, }} \Delta E W T_{\mathrm{m} \text {-GRACE, }}$ and $\Delta E W T_{\mathrm{m}-C o m b S o l}$ with respect to $\Delta E W T_{\mathrm{m}-W G H M}$ are $7 \mathrm{~cm}$, $5 \mathrm{~cm}$ and $4 \mathrm{~cm}$, respectively. The improvements, in terms of standard deviations of the differences, obtained for $\triangle E W T_{\mathrm{m} \text {-CombSol }}$ in comparison to $\triangle E W T_{\mathrm{m} \text {-GRACE }}$ are limited to $46 \%$ of the GNSS stations investigated, however, there are only $4 \%$ of the GNSS sites where standard deviations of the difference

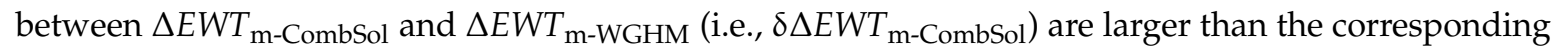
ones obtained from the differences between $\Delta E W T_{\mathrm{m} \text {-GRACE }}$ and $\triangle E W T_{\text {WGHM }}$ (i.e., $\delta \Delta E W T_{\mathrm{m} \text {-GRACE) }}$ ). In general, the combination of $\triangle E W T_{\mathrm{m}-\mathrm{GNSS}}$ and $\triangle E W T_{\mathrm{m}-\mathrm{GRACE}}$ either reduce or do not change standard deviations of $\delta \Delta E W T_{\mathrm{m} \text {-CombSol }}$ in comparison to the corresponding ones of $\delta \Delta E W T_{\mathrm{m}-\mathrm{GRACE}}$.

Although linear trends in $\Delta h$ estimated from GNSS data of the ASG-EUPOS CORS network and the corresponding ones determined from GRACE/GRACE-FO satellite missions data are not fully consistent, the agreement in the seasonal pattern of $\Delta h$ and $\triangle E W T$ obtained from these both data types demonstrates the capability of using stations of the ASG-EUPOS CORS network as sensors for the determination of temporal mass variations within the Earth's system. Moreover, incorporation of $\triangle E W T_{m \text {-GNSS }}$ to $\triangle E W T_{\mathrm{m} \text {-GRACE }}$ provides improved solutions for sensing mass variation of the Earth's surface. The $\triangle E W T_{\mathrm{m} \text {-Combsol }}$ developed from this incorporation can be thought as optimization of the determination of mass variations using GNSS data from the ASG-EUPOS CORS network and GRACE/GRACE-FO satellite mission data. This is due to the coarse spatial resolution of GRACE/GRACE-FO satellite mission data while GNSS provides local information about mass variations. Thus, $\triangle E W T_{\mathrm{m} \text {-GNSS }}$ and $\triangle E W T_{\mathrm{m} \text {-GRACE }}$ are complementary to each other.

Overall, the results obtained indicate that although national GNSS CORS networks are mainly developed for precise positioning related applications, they evidently provide a valuable information complementary to the one obtained from satellite data for the determination of temporal mass variations within the Earth's system. Data from the ASG-EUPOS CORS network in Poland improve models of temporal mass variations within the Earth's system obtained from GRACE/GRACE-FO satellite missions' 
data. However, the use of other national GNSS CORS networks operated worldwide for determining temporal mass variations within the Earth's system as well as for improving GRACE/GRACE-FO satellite missions' solutions is a subject of future investigation.

Author Contributions: Conceptualization, W.G., M.S., J.K. and J.D.R.; methodology, W.G., J.D.R., M.S. and J.K.; software, J.D.R. and W.G.; validation, J.D.R., W.G. and M.S.; formal analysis, J.D.R. and W.G.; data curation, W.G., M.S. and J.D.R.; writing — original draft preparation, W.G. and J.D.R.; writing-review and editing, M.S. and J.K.; visualization, J.D.R. and W.G.; supervision, J.K.; project administration, W.G.; funding acquisition, W.G., M.S. and J.K. All authors have read and agreed to the published version of the manuscript.

Funding: This work was supported by the Polish National Science Centre (NCN) within the research Grant No. 2017/26/D/ST10/00422.

Acknowledgments: The authors would like to acknowledge the anonymous four reviewers for their valuable and constructive comments.

Conflicts of Interest: The authors declare no conflict of interest.

\section{References}

1. Tapley, B.D.; Bettadpur, S.; Watkins, M.; Reigber, C. The gravity recovery and climate experiment: Mission overview and early results. Geophys. Res. Lett. 2004, 31, L09607. [CrossRef]

2. Wouters, B.; Bonin, J.A.; Chambers, D.P.; Riva, R.E.; Sasgen, I.; Wahr, J. GRACE, time-varying gravity, Earth system dynamics and climate change. Rep. Prog. Phys. 2014, 77, 116801. [CrossRef] [PubMed]

3. Blewitt, G.; Lavallée, D.; Clarke, P.; Nurutdinov, K. A new global mode of Earth deformation: Seasonal cycle detected. Science 2001, 294, 2342-2345. [CrossRef] [PubMed]

4. van Dam, T.; Wahr, J.; Milly, P.C.D.; Shmakin, A.B.; Blewitt, G.; Lavallée, D.; Larson, K.M. Crustal displacements due to continental water loading. Geophys. Res. Lett. 2001, 28, 651-654. [CrossRef]

5. Kusche, J.; Schrama, E.J.O. Surface mass redistribution inversion from global GPS deformation and Gravity Recovery and Climate Experiment (GRACE) gravity data. J. Geophys. Res. 2005, 110, B09409. [CrossRef]

6. Tregoning, P.; Watson, C.; Ramillien, G.; McQueen, H.; Zhang, J. Detecting hydrologic deformation using GRACE and GPS. Geoph. Res. Lett. 2009, 36, L15401. [CrossRef]

7. Rietbroek, R.; Fritsche, M.; Dahle, C.; Brunnabend, S.E.; Behnisch, M.; Kusche, J.; Flechtner, F.; Schröter, J.; Dietrich, R. Can GPS-Derived Surface Loading Bridge a GRACE Mission Gap? Surv. Geophys. 2014, 35, 1267-1283. [CrossRef]

8. Bevis, M.; Alsdorf, D.; Kendrick, E.; Fortes, L.P.; Forsberg, B.; Smalley, R., Jr.; Becker, J. Seasonal fluctuations in the mass of the Amazon River system and Earth's elastic response. Geophys. Res. Lett. 2005, 32, L16308. [CrossRef]

9. Van Dam, T.; Wahr, J.; Lavallée, D. A comparison of annual vertical crustal displacements from GPS and Gravity Recovery and Climate Experiment (GRACE) over Europe. J. Geophys. Res. 2007, 112, B03404. [CrossRef]

10. Heki, K. Dense GPS array as a new sensor of seasonal changes of surface loads. In The State of the Planet: Frontiers and Challenges in Geophysics; Sparks, R.S.J., Hawkesworth, C.J., Eds.; Geophysical Monograph Series; AGU: Washington, DC, USA, 2004; Volume 150, pp. 177-196. [CrossRef]

11. Davis, J.L.; Elósegui, P.; Mitrovica, J.X.; Tamisiea, M.E. Climate-driven deformation of the solid earth from GRACE and GPS. Geophys. Res. Lett. 2004, 31, L24605. [CrossRef]

12. Steckler, M.S.; Nooner, S.L.; Akhter, S.H.; Chowdhury, S.K.; Bettadpur, S.; Seeber, L.; Kogan, M.G. Modeling Earth deformation from monsoonal flooding in Bangladesh using hydrographic, GPS, and Gravity Recovery and Climate Experiment (GRACE) data. J. Geophys. Res. Solid Earth 2010, 115, B08407. [CrossRef]

13. Bevis, M.; Wahr, J.; Khan, S.A.; Madsen, F.B.; Brown, A.; Willis, M.; Kendrick, E.; Knudsen, P.; Box, J.E.; van Dam, T.; et al. Bedrock displacements in Greenland manifest ice mass variations, climate cycles and climate change. Proc. Natl. Acad. Sci. USA 2012, 109, 11944-11948. [CrossRef] [PubMed]

14. Nahmani, S.; Bock, O.; Bouin, M.N.; Santamaría-Gómez, A.; Boy, J.P.; Collilieux, X.; Métivier, L.; Panet, I.; Genthon, P.; De Linage, C.; et al. Hydrological deformation induced by the West African Monsoon: Comparison of GPS, GRACE and loading models. J. Geophys. Res. Solid Earth 2012, 117, B05409. [CrossRef]

15. Fu, Y.; Freymueller, J.T.; Jensen, T. Seasonal hydrological loading in southern Alaska observed by GPS and GRACE. Geophys. Res. Lett. 2012, 39, L15310. [CrossRef] 
16. Chew, C.C.; Small, E.E. Terrestrial water storage response to the 2012 drought estimated from GPS vertical position anomalies. Geophys. Res. Lett. 2014, 41, 6145-6151. [CrossRef]

17. Fu, Y.; Argus, D.F.; Landerer, F.W. GPS as an Independent Measurement to Estimate Terrestrial Water Storage Variations in Washington and Oregon. J. Geophys. Res. Solid Earth 2015, 120, 552-566. [CrossRef]

18. Tan, W.; Dong, D.; Chen, J.; Wu, B. Analysis of systematic differences from GPS-measured and GRACE-modeled deformation in Central Valley, California. Adv. Space Res. 2016, 57, 19-29. [CrossRef]

19. Liu, R.L.; Li, J.; Fok, H.S.; Shum, C.K.; Li, Z. Earth surface deformation in the North China plain detected by joint analysis of GRACE and GPS data. Sensors 2014, 14, 19861-19876. [CrossRef]

20. Zhang, X.; Jin, S.; Lu, X. Global Surface Mass Variations from Continuous GPS Observations and Satellite Altimetry Data. Remote Sens. 2017, 9, 1000. [CrossRef]

21. Jiang, W.; Yuan, P.; Chen, H.; Cai, J.; Li, Z.; Chao, N.; Sneeuw, N. Annual variations of monsoon and drought detected by GPS: A case study in Yunnan, China. Sci. Rep. 2017, 7, 5874. [CrossRef]

22. Zhong, B.; Li, X.; Chen, J.; Li, Q.; Liu, T. Surface Mass Variations from GPS and GRACE/GFO: A Case Study in Southwest China. Remote Sens. 2020, 12, 1835. [CrossRef]

23. Zou, R.; Wang, Q.; Freymueller, J.T.; Poutanen, M.; Cao, X.; Zhang, C.; Yang, S.; He, P. Seasonal hydrological loading in southern Tibet detected by joint analysis of GPS and GRACE. Sensors 2015, 15, 30525-30538. [CrossRef] [PubMed]

24. Pan, Y.; Shen, W.B.; Hwang, C.; Liao, C.; Zhang, T.; Zhang, G. Seasonal Mass Changes and Crustal Vertical Deformations Constrained by GPS and GRACE in Northeastern Tibet. Sensors 2016, 16, 1211. [CrossRef] [PubMed]

25. Rajner, M.; Liwosz, T. Studies of crustal deformation due to hydrological loading on GPS height estimates. Geod. Cartogr. 2011, 60, 135-144. [CrossRef]

26. Godah, W.; Szelachowska, M.; Ray, J.D.; Krynski, J. Comparison of vertical deformation of the Earth's surface obtained using GRACE-based GGMS and GNNS data-A case study of South-Eastern Poland. Acta Geodyn. Geomater. 2020, 17, 169-176. [CrossRef]

27. Birhanu, Y.; Bendick, R. Monsoonal loading in Ethiopia and Eritrea from vertical GPS displacement time series. J. Geophys. Res. Solid Earth 2015, 120, 7231-7238. [CrossRef]

28. Eriksson, D.; MacMillan, D.S. Continental hydrology loading observed by VLBI measurements. J. Geod. 2014, 88, 675-690. [CrossRef]

29. Bettadpur, S. Gravity Recovery and Climate Experiment Level-2 Gravity Field Product User Handbook. Cent. Space Res. Univ. Tex. Austin 2018. Available online: https://podaac-tools.jpl.nasa.gov/drive/files/allData/ grace/docs/L2-UserHandbook_v4.0.pdf (accessed on 19 July 2020).

30. Dahle, C.; Flechtner, F.; Murböck, M.; Michalak, G.; Neumayer, K.H.; Abrykosov, O.; Reinhold, A.; König, R. GRACE-FO Geopotential GSM Coefficients GFZ RL06. V. 6.0. GFZ Data Serv. 2019. [CrossRef]

31. Dahle, C.; Flechtner, F.; Murböck, M.; Michalak, G.; Neumayer, K.H.; Abrykosov, O.; Reinhold, A.; König, R. GRACE Geopotential GSM Coefficients GFZ RL06. V. 6.0. GFZ Data Serv. 2018. [CrossRef]

32. Yuan, D.-N. GRACE Follow-On Level-2 Gravity Field Product User Handbook. Jet Propulsion Laboratory, JPL D-103922 2019. Available online: https://podaac-tools.jpl.nasa.gov/drive/files/allData/gracefo/docs/GRACEFO_L2-UserHandbook_v1.0.pdf (accessed on 18 August 2020).

33. Luthcke, S.B.; Sabaka, T.J.; Loomis, B.D.; Arendt, A.A.; McCarthy, J.J.; Camp, J. Antarctica, Greenland and Gulf of Alaska land ice evolution from an iterated GRACE global mascon solution. J. Glac. 2013, 59, 613-631. [CrossRef]

34. Watkins, M.M.; Xiang, L.; Jia, L.; Jiang, L.; Wang, Z.; Hu, B.; Gao, P. Improved methods for observing Earth's time variable mass distribution with GRACE using spherical cap mascons. J. Geophys. Res. Solid Earth 2015, 120, 2648-2671. [CrossRef]

35. Save, H.; Bettadpur, S.; Tapley, B.D. High resolution CSR GRACE RL05 mascons. J. Geophys. Res. Solid Earth 2016, 121, 7547-7569. [CrossRef]

36. Larson, K.M.; Small, E.E.; Chew, C.C.; Nievinski, F.G.; Pratt, J.; McCreight, J.L.; Braun, J.; Boniface, K.; Evans, S.G. PBO H2O: Plate Boundary Observatory Studies of the Water Cycle. In Proceedings of the American Geophysical Union, Fall Meeting, San Francisco, CA, USA, 9-13 December 2013. S21A-2373.

37. Ray, J.; Altamimi, Z.; Collilieux, X.; van Dam, T. Anomalous harmonics in the spectra of GPS position estimates. GPS Solut. 2008, 12, 55-64. [CrossRef] 
38. Kusche, J.; Schmidt, R.; Petrovic, S.; Rietbroek, R. Decorrelated GRACE time-variable gravity solutions by GFZ, and their validation using a hydrological model. J. Geod. 2009, 83, 903-913. [CrossRef]

39. Godah, W.; Szelachowska, M.; Krynski, J. On the analysis of temporal geoid height variations obtained from GRACE-based GGMs over the area of Poland. J. Acta Geophys. 2017, 65, 713-725. [CrossRef]

40. Müller Schmied, H. Evaluation, Modification and Application of Global Hydrological Model; Frankfurt Hydrology Paper 16; Institute of Physical Geography, Goethe University Frankfurt: Frankfurt am Main, Germany, 2017; Available online: https://www.uni-frankfurt.de/65883413/Mueller_Schmied_2017_evaluation_modification_ and_application_of_a_global_hydrological_model.pdf (accessed on 19 July 2020).

41. Müller Schmied, H.; Eisner, S.; Franz, D.; Wattenbach, M.; Portmann, F.T.; Flörke, M.; Döll, P. Sensitivity of simulated global-scale freshwater fluxes and storages to input data, hydrological model structure, human water use and calibration. Hydrol. Earth Syst. Sci. 2014, 18, 3511-3538. [CrossRef]

42. Wahr, J.; Molenaar, M.; Bryan, F. Time variability of the Earth's gravity field: Hydrological and oceanic effects and their possible detection using GRACE. J. Geophys. Res. 1998, 103, 30205-30229. [CrossRef]

43. Godah, W. IGiK-TVGMF: A MATLAB package for computing and analysing temporal variations of gravity/mass functionals from GRACE satellite based global geopotential models. Comput. Geosci. 2019, 123, 47-58. [CrossRef]

44. Dziewonski, A.; Anderson, D.L. Preliminary reference Earth model. Phys. Earth Planet. Inter. 1981, 25, 297-356. [CrossRef]

45. Wang, H.; Xiang, L.; Jia, L.; Jiang, L.; Wang, Z.; Hu, B.; Gao, P. Load Love numbers and Green's functions for elastic Earth models PREM, iasp91, ak135, and modified models with refined crustal structure from Crust 2.0. Comp. Geosci. 2012, 49, 190-199. [CrossRef]

46. Holmes, S.A.; Featherstone, W.E. A unified approach to the Clenshaw summation and the recursive computation of very high degree and order normalised associated Legendre functions. J. Geod. 2002, 76, 279-299. [CrossRef]

47. Sun, Y.; Riva, R.; Ditmar, P. Optimizing estimates of annual variations and trends in geocenter motion and J2 from a combination of GRACE data and geophysical models. J. Geophys. Res. Solid Earth 2016, 121, 8352-8370. [CrossRef]

48. Cheng, M.K.; Ries, J.C. The unexpected signal in GRACE estimates of C20. J. Geod. 2017, 91, 897-914. [CrossRef]

49. Pavlis, N.K.; Holmes, S.A.; Kenyon, S.C.; Factor, J.K. The development and evaluation of the earth gravitational model 2008 (EGM2008). J. Geophys. Res. 2012, 117, B04406. [CrossRef]

50. Herring, T.A. MATLAB tools for viewing GPS velocities and time series. GPS Solut. 2003, 7, 194-199. [CrossRef]

51. Herring, T.A.; King, R.W.; McClusky, S.C. GAMIT Reference Manual, GPS analysis at MIT Release 10.7; Mass. Inst. Technol. USA: Cambridge, MA, USA, 2018; pp. 1-168.

52. Estey, L.H.; Meertens, C.M. TEQC: The multi-purpose toolkit for GPS/GLONASS data. GPS Solut. 1999, 3, 42-49. [CrossRef]

53. Schaer, S.; Gurtner, W.; Feltens, J. IONEX: The ionosphere map exchange format version 1. In Proceedings of the IGS Analysis Center Workshop, Darmstadt, Germany, 9-11 February 1998; pp. 233-247.

54. Kouba, J. Implementation and testing of the gridded Vienna Mapping Function 1 (VMF1). J. Geod. 2008, 82, 193-205. [CrossRef]

55. Lagler, K.; Schindelegger, M.; Böhm, J.; Krásná, H.; Nilsson, T. GPT2: Empirical slant delay model for radio space geodetic techniques. Geophys. Res. Lett. 2013, 40, 1069-1073. [CrossRef]

56. Tregoning, P.; van Dam, T. Atmospheric pressure loading corrections applied to GPS data at the observation level. Geophys. Res. Lett. 2005, 32, L22310. [CrossRef]

57. Lyard, F.; Lefevre, F.; Letellier, T.; Francis, O. Modelling the global ocean tides: Modern insights from FES2004. Ocean Dyn. 2006, 56, 394-415. [CrossRef]

58. Altamimi, Z.; Rebischung, P.; Métivier, L.; Collilieux, X. ITRF2014: A new release of the International Terrestrial Reference Frame modeling nonlinear station motions. J. Geophys. Res. Solid Earth 2016, 121, 6109-6131. [CrossRef]

59. Geirsson, H.; Árnadóttir, T.; Völksen, C.; Jiang, W.; Sturkell, E.; Villemin, T.; Einarsson, P.; Sigmundsson, F.; Stefánsson, R. Current plate movements across the Mid-Atlantic Ridge determined from 5 years of continuous GPS measurements in Iceland. J. Geophys. Res. 2006, 111, B09407. [CrossRef] 
60. Krynski, J.; Kloch-Główka, G.; Szelachowska, M. Analysis of time variations of the gravity field over Europe obtained from GRACE data in terms of geoid height and mass variations. In Earth on the Edge: Science for a Sustainable Planet; Rizos, C., Willis, P., Eds.; Springer: Berlin/Heidelberg, Germany, 2014; Volume 139, pp. 365-370. [CrossRef]

61. Romagnoli, C.; Zerbini, S.; Lago, L.; Richter, B.; Simon, D.; Domenichini, F.; Ghirotti, M. Influence of soil consolidation and thermal expansion effects on height and gravity variations. J. Geodyn. 2003, 35, 521-539. [CrossRef]

62. Silverii, F.; d'Agostino, N.; Métois, M.; Fiorillo, F.; Ventafridda, G. Transient deformation of karst aquifers due to seasonal and multiyear groundwater variations observed by GPS in southern Apennines (Italy). J. Geophys. Res. Solid Earth 2016, 121, 8315-8337. [CrossRef]

63. Penna, N.T.; Stewart, M.P. Aliased tidal signatures in continuous GPS height time series. Geophys. Res. Lett. 2003, 30, 2184. [CrossRef]

64. Amiri-Simkooei, A.R. On the nature of GPS draconitic year periodic pattern in multivariate position time series. J. Geophys. Res. Solid Earth 2013, 118, 2500-2511. [CrossRef]

65. Chanard, K.; Métois, M.; Rebischung, P.; Avouac, J.P. A warning against over-interpretation of seasonal signals measured by the Global Navigation Satellite System. Nat. Commun. 2020, 11, 1-4. [CrossRef] [PubMed]

66. Kuczynska-Siehien, J.; Piretzidis, D.; Sideris, M.G.; Olszak, T.; Szabó, V. Monitoring of extreme land hydrology events in central Poland using GRACE, land surface models and absolute gravity data. J. Appl. Geod. 2019, 13, 229-243. [CrossRef]

67. Szafranek, K.; Bogusz, J.; Figurski, M. GNSS reference solution for permanent station stability monitoring and geodynamical investigations: The ASG-EUPOS case study. Acta Geodyn. Geomater. 2013, 10, 67-75. [CrossRef]

68. Kontny, B.; Bogusz, J. Models of vertical movements of the Earth crust surface in the area of Poland derived from leveling and GNSS data. Acta Geodyn. Geomater. 2012, 9, 331-337.

69. Kowalczyk, K. The creation of a model of relative vertical crustal movements in the Polish territory on the basis of the data from active geodetic network EUPOS (ASG EUPOS). Acta Geodyn. Geomater. 2015, 12, 215-225. [CrossRef]

70. Scanlon, B.R.; Zhang, Z.; Rateb, A.; Sun, A.; Wiese, D.; Save, H.; van Beek, R. Tracking seasonal fluctuations in land water storage using global models and GRACE satellites. Geophys. Res. Lett. 2019, 46, 5254-5264. [CrossRef]

Publisher's Note: MDPI stays neutral with regard to jurisdictional claims in published maps and institutional affiliations.

(C) 2020 by the authors. Licensee MDPI, Basel, Switzerland. This article is an open access article distributed under the terms and conditions of the Creative Commons Attribution (CC BY) license (http://creativecommons.org/licenses/by/4.0/). 